Florida International University FIU Digital Commons

7-25-1991

\title{
Population ecology of the bald eagle (Haliaeetus leucocephalus) in Florida Bay, Everglades National Park, Florida, 1959-1990
}

John L. Curnutt

Florida International University

DOI: $10.25148 /$ etd.FI14061572

Follow this and additional works at: https://digitalcommons.fiu.edu/etd

Part of the Biology Commons

\section{Recommended Citation}

Curnutt, John L., "Population ecology of the bald eagle (Haliaeetus leucocephalus) in Florida Bay, Everglades National Park, Florida, 1959-1990" (1991). FIU Electronic Theses and Dissertations. 2696.

https://digitalcommons.fiu.edu/etd/2696

This work is brought to you for free and open access by the University Graduate School at FIU Digital Commons. It has been accepted for inclusion in FIU Electronic Theses and Dissertations by an authorized administrator of FIU Digital Commons. For more information, please contact dcc@fiu.edu. 
Population Ecology of the Bald Eagle (haliaeetus leucocephalus) in Florida Bay, Everglades National Park, Florida, 1959 - 1990

by

John L. Curnutt

Florida International University, 1991

Miami, Florida

Professor George H. Dalrymple, Major Professor

Using aerial census techniques, I collected data on the population, reproduction and nesting habits of Bald Eagles in Florida Bay, Florida, for three consecutive breeding seasons (Oct - Mar, 1987 - 1990). For analysis I consolidated my data with those collected by Robertson et al. between 1959 and 1986 for a total of 26 seasons. The breeding population of Bald Eagles in Florida Bay has been stable since censuses began in 1959. However, numbers of subadult eagles in Florida Bay have declined sharply since the early 1960's. Breeding density was apparently limited by territoriality. Nesting success was positively correlated with early commencement of nesting, number of active breeding territories and the history of individual breeding territories. Success 
was negatively correlated with the amount of rainfall during the breeding season. Most (87\%) nesting failures occurred during the incubation stage. Nearly all nests were built in mangrove (Laguncularia racemosa, Avtcenia germinans and Rhizophora mangle) trees and of these more than half were dead. The success of a nesting attempt was independent of changes in nests or nest sites. 
FLORIDA INTERNATIONAL UNIVERSITY

Miami, Florida

Population Ecology of the Bald Eagle (haliaeetus leucocephalus) in Florida Bay, Everglades National Park, Florida, 1959-1990

\begin{abstract}
A thesis submitted in partial satisfaction of the requirements for the degree of Master of Science in Biology
\end{abstract}

by

John L. Curnutt 
This thesis, having been approved in respect to form and mechandcal execution is referred to you for judgement upon its substantial merit.

Dean Art Herriot

College of Arts and Sciences

The thesis of John L. Curnutt Is approved.

Dr. William B. Robertson, Jr.

Dr. Martin Tracey

Dr. George H. Dalrymple, Major Professor

Date of Examination: 25 July. 1991

Dean Richard Campbell

Division of Graduate Studies 
Copyright by

John L. Curnutt

1991 


\section{ACKNOWLEDGEMENTS}

This study was conducted as part of the Endangered Species Inventory and Monitoring Project at the South Florida Research Center of Everglades National Park. Funding was provided by the National Park Service.

I would like to thank Dr. George Dalrymple, my committee chairman, for his very helpful instruction in both ecology and statistics. Also, I am very grateful to my committee members, Dr. Marty Tracey and Dr. Bill Robertson. I owe special thanks to Dr. Bill for sharing with me more knowledge than I could absorb and for allowing me to work with the Bald Eagle data that he had the foresight to begin collecting 30-odd years ago. I also thank my wife for her occastonal field work, frequent editing, and continuous understanding and my parents for their much-needed and frequent support.

Bill Robertson had the help of a number of people in the collection of the data included in the analysis of this study Including John Ogden, Sandy Sprunt, Sonny Bass, David Shea, Marty Fleming. John Ladley, and many others. 


\section{INTRODUCTION}

Purpose of research

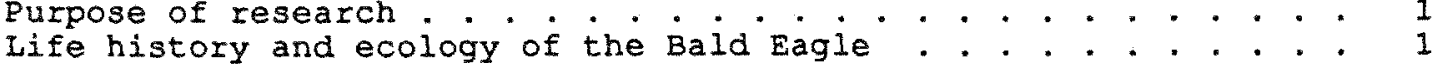

History of Bald Eagle research in ENP . . . . . . . . . . . . . . 2

STUDY AREA . . . . . . . . . . . . . . . . . . . . . . . . . . 2

METHODS AND MATERIAL . . . . . . . . . . . . . . . . . . 8

Terminology............................ . . 8

Aerial surveys . . . . . . . . . . . . . . . . . . . . . 8

Ground searches... . . . . . . . . . . . . . . . . . . . 9

Nesting chronology . . . . . . . . . . . . . . . . . . . . . 9

Nest-sites . . . . . . . . . . . . . . . . . . . 10

Database .. . . . . . . . . . . . . . . . . . . 10

Analysis .......................... . . . . 10

RESULTS . . . . . . . . . . . . . . . . . . . . . . . . . . . . . 11

Surveys ............................. . . . . 11

Territories.......................... . . . . 11

Reproduction ........................... . 19

Nest-sites . . . . . . . . . . . . . . . . . . . . . . . . 43

Reproductive Quality of Territories. . . . . . . . . . . . . . 51

DISCUSSION . . . . . . . . . . . . . . . . . . . . . . 52

Breeding Chronology . . . . . . . . . . . . . . . . . . . . . . 52

Population and Distribution . . . . . . . . . . . . . . . . 52

Reproduction . . . . . . . . . . . . . . . . . . . 56

Relationships between reproduction and nest site........ . 59

Nest Sites . . . . . . . . . . . . . . . . . . . . . 59

CONCLUSION . . . . . . . . . . . . . . . . . . . . . . . . 62

LITERATURE CITED . . . . . . . . . . . . . . . . . . . . 63 
Table 1. Numbers of observations at Florida Bay Bald Eagle territories. . . . . . . . . . . . . . . . . . . . 13

Table 2. Summary statistics of the chronology of nesting by Bald Eagles in Florida Bay, 1959 - 1989. . . . . . . . . . . . . . 20

Table 3. Comparisons of the chronology of nesting activity between successful and unsuccessful Bald Eagle nesting attempts in Florida bay, 1959 - 1989, using independent t-tests. . . . . . . 21

Table 4. Bald Eagle reproduction in Florida Bay, 1959 - 1989 (n = 26). . . . . . . . . . . . . . . . . 28

Table 5. Bald Eagle reproduction in Florida Bay, 1959 - 1989, by roughly 5 -year intervals. . . . . . . . . . . . . . . . . . . 33

Table 6. Correlation matrix and probabilities (in parentheses) of Bald Eagle reproductive results in Elorida Bay, $1959-1989$ (n $=26$, $\mathrm{df}=25$ for all tests). Shading indicates significance. . . . .

Table 7. Correlations and probabilities (in parentheses) of Bald Eagle reproductive activity and adult population, $1959-1989$ (n $=26$, $\mathrm{df}=25$ for all cells). Shading indicates significance. . . .

Table 8. Types of nest trees used by Bald Eagles in Florida Bay, 1959 -1989 seasons. Snags are standing dead trees and "partially live" are trees with a dead center stem and live sprouts emanating from the base. . . . . . . . . . . . . . . . . .

Table 9. Comparison of nest age, DBH and tree height for Avicenia and Rhizophora Bald Eagle nest trees in Florida Bay, 1959-1989.. . . 46

Table 10. Comparison of nest age, DBH, and tree height for dead and living Bald Eagle nest trees, Florida Bay, 1959-1989. ... . . . 47

Table 11. Characteristics of Bald Eagle nest sites from various studies. 


\section{LIST OF EIGURES}

Eigure 1. Annual rainfall (in inches) recorded at Flamingo Ranger Station, 1959 - 1989. . . . . . . . . . . . . . . . . . 6

Figure 2. Average monthly rainfall (in inches) and ranges for Flamingo Ranger Station, 1959 - 1989. . . . . . . . . . . . . . . . . 7

Figure 3. Major habitat types of Everglades National Park. . . . . . . 8

Figure 4. Bald Eagle nest sites of Everglades National Park, 1959 1989. . . . . . . . . . . . . . . . . . . . . . 9

Figure 5. Frequency distribution of numbers of census flights per Bald Eagle breeding season at Florida Bay, 1959 - 1989.

Figure 6. The distribution of 3674 observations of Florida Bay Bald Eagle territories in which there were nesting attempts, 1959 1989.

Eigure 7. Thirty-one historically defined Bald Eagle breeding territories in Florida Bay, 1959 - 1989. . . . . . . . . . . .

Eigure 8. Index of aggragation (Clark and Evans in Krebs 1989) for active Bald Eagle territories in Florida Bay, 1959 - 1989. . .

Figure 9. Cumulative observed and expected distances between active Bald Eagle territories in Florida Bay, 1959-1989. . . . . . .

Figure 10. The distribution of observed reproductive activity (by Julian Date) of Bald Eagles in Florida Bay, 1959 - 1989 ( $\mathrm{n}=$ 3674). . . . . . . . . . . . . . . . . . . . .

Figure 11. Means and ranges of seven stages of Bald Eagle nesting activity in Florida Bay for successful and unsuccessful nesting attempts.

Figure 12. Means and ranges of seven stages of Bald Eagle nesting activity for eastern and western portions of Florida Bay. . . . . 26

Figure 13. Breeding and nonbreeding adult Bald Eagle populations of Florida Bay, Everglades National Park, 1959 - 1989. . . . . . .

Eigure 14. Number of subadult Bald Eagles observed per hour of aerial census in Florida Bay, 1959 - 1989. . . . . . . . . . . . . . .

Figure 15. Percent of observed Bald Eagle territories in Florida Bay that were active, 1959 - 1989.

Figure 16. Frequency distribution of the number of Bald Eagle fledglings produced at active nests in Florida Bay, 1959 1989 .

Figure 17. Bald Eagle young produced per nesting attempt and per nesting success reported from various studies. . . . . . . . .

Figure 18. Number of nonbreeding adult Bald Eagles vs number of active territories and nesting attempts, Florida Bay, 1959 - 1989. . .

Figure 19. The relationship between the number of Bald Eagles produced per nesting attempt and the number of active territories and nesting attempts, Florida Bay, 1959 - 1989. . . . . . . . . 
Figure 20. The relationship between the number of Bald Eagles produced per successful nesting attempt to the number of active territories, nesting attempts and nesting successes, Florida bay, $1959-1989$.

40

Figure 21. Mean dates and ranges of Bald Eagle nesting failure in Florida Bay when nests were in the incubation stage, 1959 1989. . . . . . . . . . . . . . . . . . . . .

42

Figure 22. Mean date of Bald Eagle nesting failure in Florida Bay vs cumulative rainfall (in inches) during the nesting season (Dec Mar), 1959 - 1989. . . . . . . . . . . . . . . . . . . . .

43

Figure 23. Observed frequencies of monthly rainfall when Bald Eagle nesting failures occurred vs those expected by the distribution of all Nov - April monthly totals, Florida Bay, 1959 - 1989.

44

Figure 24. The number of new Bald Eagle nests built each season in Florida Bay, 1959 - 1989. The mean of 4.95 nests does not include seasons 1960 and 1965 .

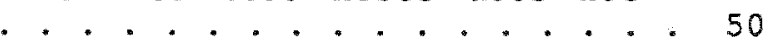

Figure 25. The proportional distribution of the area (ha) of all keys in Florida Bay vs those on which Bald Eagles have nested, 1959 1989. Two keys $(163.4$ ha and $318 \mathrm{ha})$ are not included, neither had nests.

Figure 26. Reproductive values $\left(\frac{f}{5}\right.$ seasons active $x$ ave. number of young fledged/active season) for 31 Bald Eagle nesting territories in Florida Bay, 1959 - 1989. . . . . . . . . . . . . 52

vil 
Purpose of research - This study describes Bald Eagle (Haliaeetus leucocephalus) reproduction and nest-sites in Florida Bay, Everglades National Park (ENP) over a 31 year period. Although the Bald Eagle is the most studied diurnal raptor in North America (Palmer 1988), I believe the population of Florida Bay provided the following rare opportunities for ecological investigation: 1) The length and continuity of the database involved in this work is rarely attained for a large, top-level consumer, 2) Southern Florida, with its sub-tropical climate and vegetation, is the extreme southeastern limit of the species' range, and 3) The nesting population is probably at its natural (i.e., pre-European settlement) density, having been spared the devastation of pesticide poisoning and habitat loss that eliminated or greatly reduced the populations of most other areas.

The Bald Eagle is found throughout North America from coast to coast as far north as the arctic and south into northern Mexico (Amadon 1983). It is a large (length $71-96 \mathrm{~cm}$, weight $3-6.3 \mathrm{~kg}$, southern birds at lower range) raptor that feeds primarily on fish and, therefore, is usually found close to water (Palmer and Gerrard in Palmer 1988).

As the national emblem of the United States the Bald Eagle has enjoyed a higher degree of attention and acceptance than most raptors ever attain. However, there have always been those who persecuted Bald Eagles under the incorrect presumption that they preyed upon livestock (and even small children), or who indiscriminately shot eagles for pleasure (Barnes 1951, Smith 1969). As a result, population levels began to decline with the expansion of Europeans into North America. Beginning in the 1940's the most serious threat to Bald Eagles became the widespread use of organochloride based pesticides, especially DDT and DDE, which caused eggshell thinning and resulted in low reproduction (Gerrard and Bortolotti 1988 et al.). The rapid decline in eagle populations that followed led the U. S. Fish and wildife 
Service to list the Bald Eagle as an endangexed species in 1967 (32 Federal Register 4001). With the banning of DDT in 1972, populations showed encouraging signs of recovery (Grier 1982a); but presently most nesting eagles (over 90\%) are still found in relict populations in Florida, the Chesapeake Bay area, the Great Lakes, Maine, and the Pacific Northwest (Green in simons et al. 1988). As a result of successful reintroduction programs the Fish and Wildife Service has proposed changing the status of the Bald Eagle to threatened (USFWS 1990). However, habitat loss and increased human interference are still causing declines in some populations (i.e., Brown $1975)$.

Life history and ecology of the Bald Eagle - Unless otherwise noted, the following is taken from Palmer's (1988) exhaustive review of available information on the Bald Eagle. Information concerning Bald Eagles in ENP is from personal communications with Dr. William B. Robertson, Jr. (Research Scientist, South Florida Research Center, ENP) or from my own observations.

Description - Bald Eagles take up to five years to attain the familiar white head and tail and dark-brown body plumage of adults. Fledglings are nearly uniform dark-brown with white speckling under the wings and base of tail. Each year thereafter, molting brings about a confusing and highly variable array of dark and white patterns, with only the cere, tail and iris following a more or less progressive change toward a definitive adult condition (see McCollough 1989 for details).

Habitat - Bald Eagles are usually found near open bodies of water where prey is concentrated, $i . e$. estuaries, large lakes and rivers, and coastal areas. Nesting is usually in larger, taller, older trees of a stand with much geographic variation in tree species chosen. Apparently, some preference exists for emergent live trees where nests are built within the canopy and sheltered from above by foliage. 
Distribution and migration - In general, Bald Eagles are found throughout North America (south to northern Mexico). The northern part of the range, from interior Alaska south to interior British Columbia and northern Alberta and east to the Maritime Provinces, is occupied only during the summer breeding season. Bald Eagles are year-round residents in coastal Alaska, south to northern California, the Great Lakes/St. Lawrence River, the northern Atlantic coast of the U.S., Florida, and the U.S. Gulf Coast. Throughout the rest of its range it occurs as a migrant, winter visitor, and scattered breeder.

Generally, northern breeding Bald Eagles migrate south to open (unfrozen) water and areas of concentrated prey. Bald Eagles in Florida, especially juveniles and sub-adults, show a varying but generally northward migration in the summer (Broley 1947). Migration of ENP birds has not been studied sufficiently to permit any conclusions.

Reproduction - Most Bald Eagles begin breeding activity at 5 years of age, although 4-year-old eagles have been observed nesting. Pair-bonding is believed to be life-long monogamy, with replacement of lost mates occurring by the surviving mate accepting another bird at its nest. Nests are often re-used with the structure becoming larger after each annual refurbishing. Initiation and length of the breeding season show geographic variation with greater spread in southern areas than in northern. In the north, egg laying occurs during March and April. In the south egg-laying may begin as early as late october and as late as January. In all cases incubation is 35 days and the nestling stage is about 77 days. If failure occurs during early incubation, the female may lay a replacement clutch as late as March.

Survival - Although Bald Eagles have been known to live up to 48 years in captivity (Terres in McGehee and Crawford 1985), too little is known of survival rates in the wild to comment. Estimates for 3-year-old birds range from a minimum of $20 \%$ survival (Gerrard et al. in Palmer 1988) to a maximum of $91 \%$ survival (McCollough in Palmer 1988). 
Food - Foods consumed by Bald Eagles vary considerably with location, season, availability, and possibly individual preference. In general, fish is the principal food source followed by waterfowl, seabirds and mammals. Carrion is taken readily, as is human refuse. In Florida Bay, fish and various birds make up the bulk of the diet (Robertson and Curnutt, unpubl. data).

History of Bald Eagle research in ENP - Records of Bald Eagles nesting in ENP date back to the mid-1880's, but only casual records of nesting activity in ENP were available until 1958 when alarm over declining eagle populations nationwide led to an intensive aerial survey of all potential nest sites in the park (Robertson pers. comm.). Bald Eagle nesting censuses have been conducted by Robertson and others almost annually since then. I began conducting censuses in February 1988 with Robertson and have continued each year to the present. Scattered records of prey items collected from eagle nests in Florida Bay and casual observations of activity at a Bald Eagle communal roost near Mahogany Hammock, ENP, date back to the late 1950's. In 1989 I began a two-year food-habits study in Florida Bay and in April 1990 I started a one-year study of eagle use of the Mahogany Hammock roost.

\section{STUDY AREA}

ENP is a 1.3 million acre sub-tropical wilderness at the southern tip of the Florida peninsula. Rainfall averaged $45.45 \pm 2.613$ inches per year over the course of the study (Fig. I). Most rain fell during the summer months (Jun Sep; Fig. 2). Craighead (1971) included the following major habitat types in ENP: Florida Bay, saline mangrove zone, freshwater wetlands, and pinelands (Eig. 3). Bald Eagle nesting habitat is limited to Florida Bay, the Gulf Coast and, to a lesser extent, the rivers and bays of the southwest interior of ENP (Fig. 4).

Florida Bay is a large $\left(1300+\mathrm{km}^{2}\right)$ estuary bounded on the north by the mainland of the Florida peninsula, on the east and south by the large Upper Florida Keys, and opens to the Gulf of Mexico to the west. Craighead (1971) describes three communities in Florida Bay as follows: 
Mud flats - Large areas flooded from 1 to $2.5 \mathrm{~m}$ feet deep, consisting mostly of marl-like mud with turtle grass (Thallasia testudinum). Many square kilometers of mud flats are exposed during low tides. 


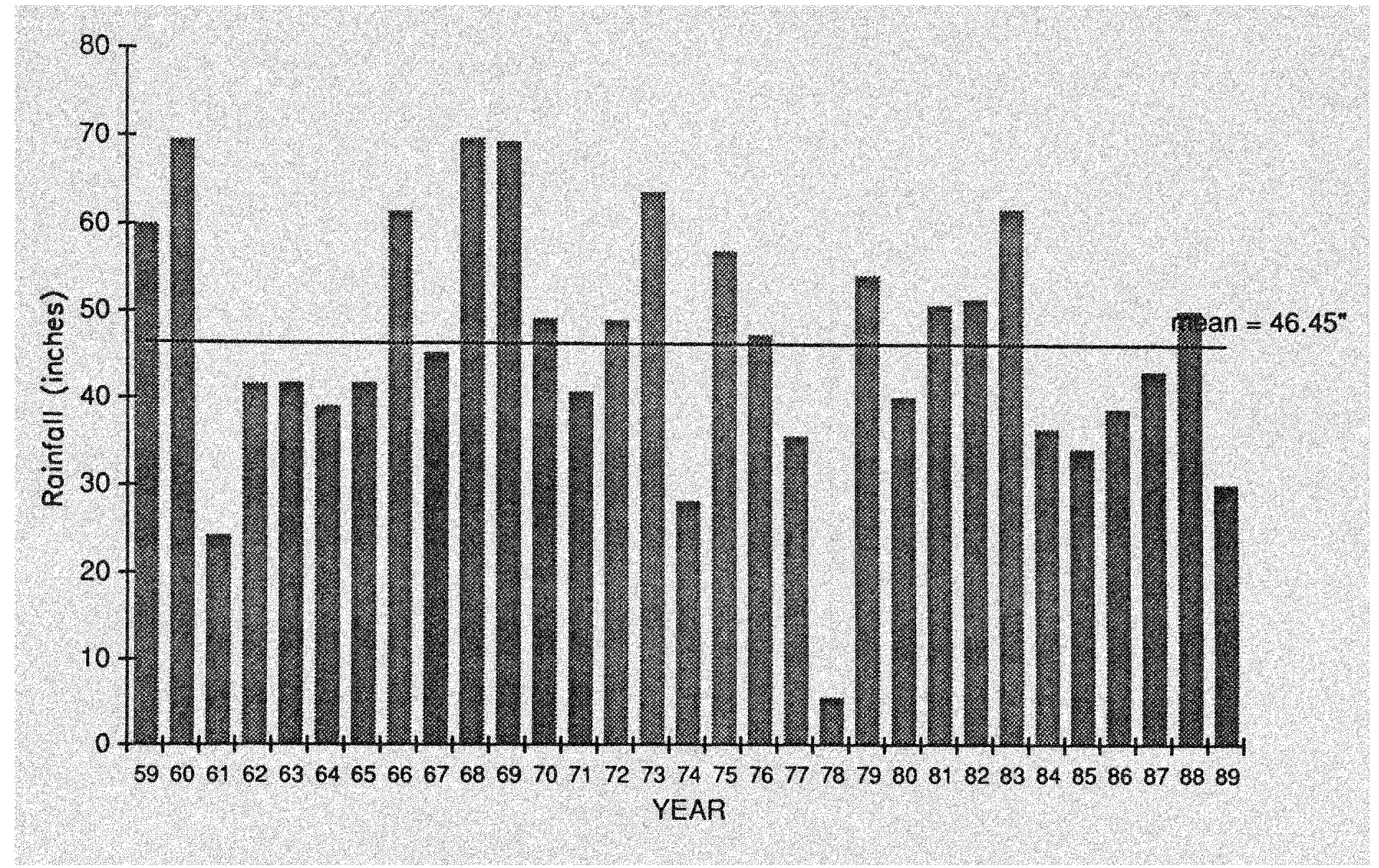

Eigure 1. Annual rainfall (in inches) recorded at Flamingo Ranger Station, $1959-1989$. 


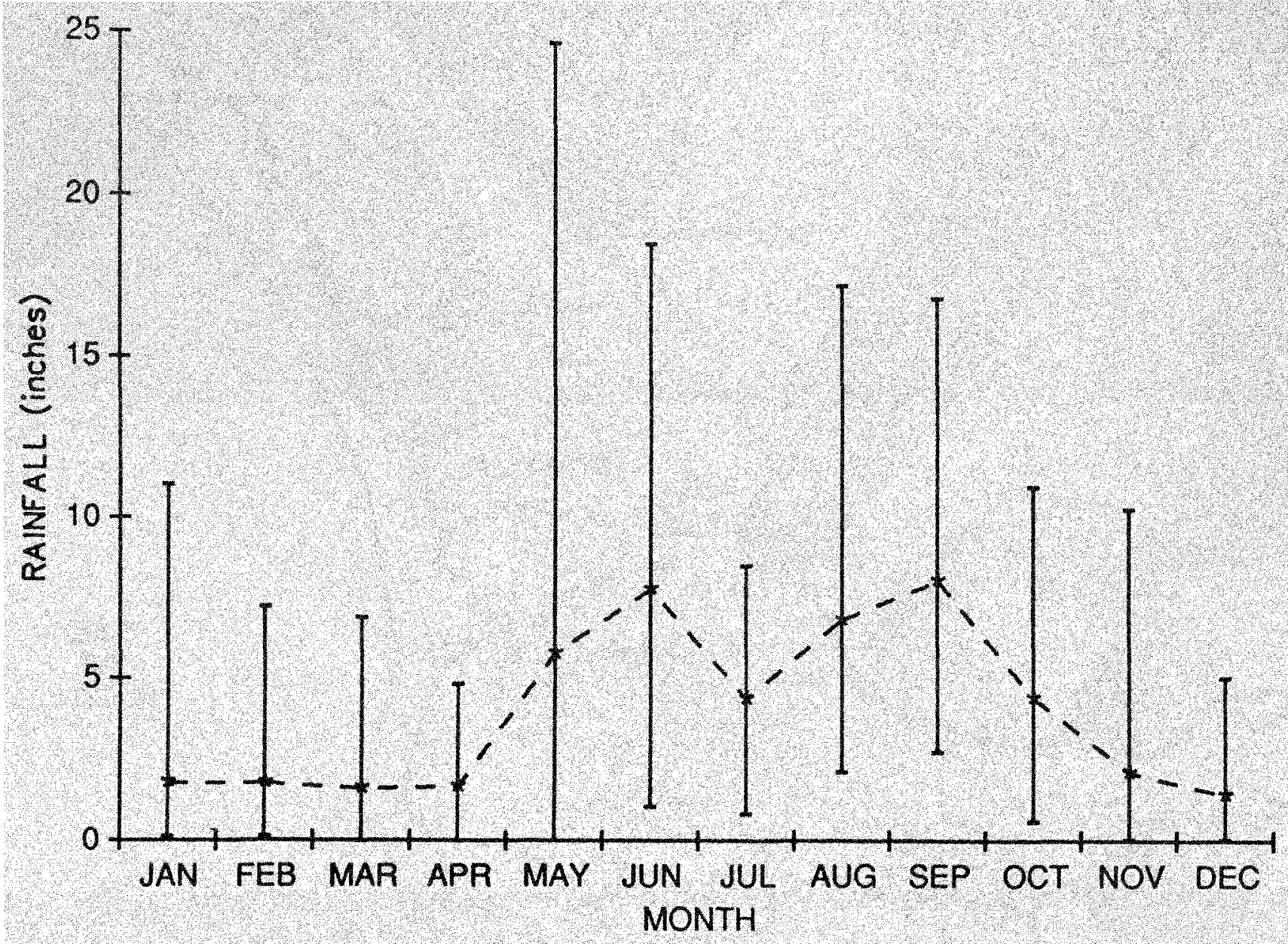

Figure 2. Average monthly rainfall (in inches) and ranges for Flamingo Ranger Station, 1959 - 1989. 


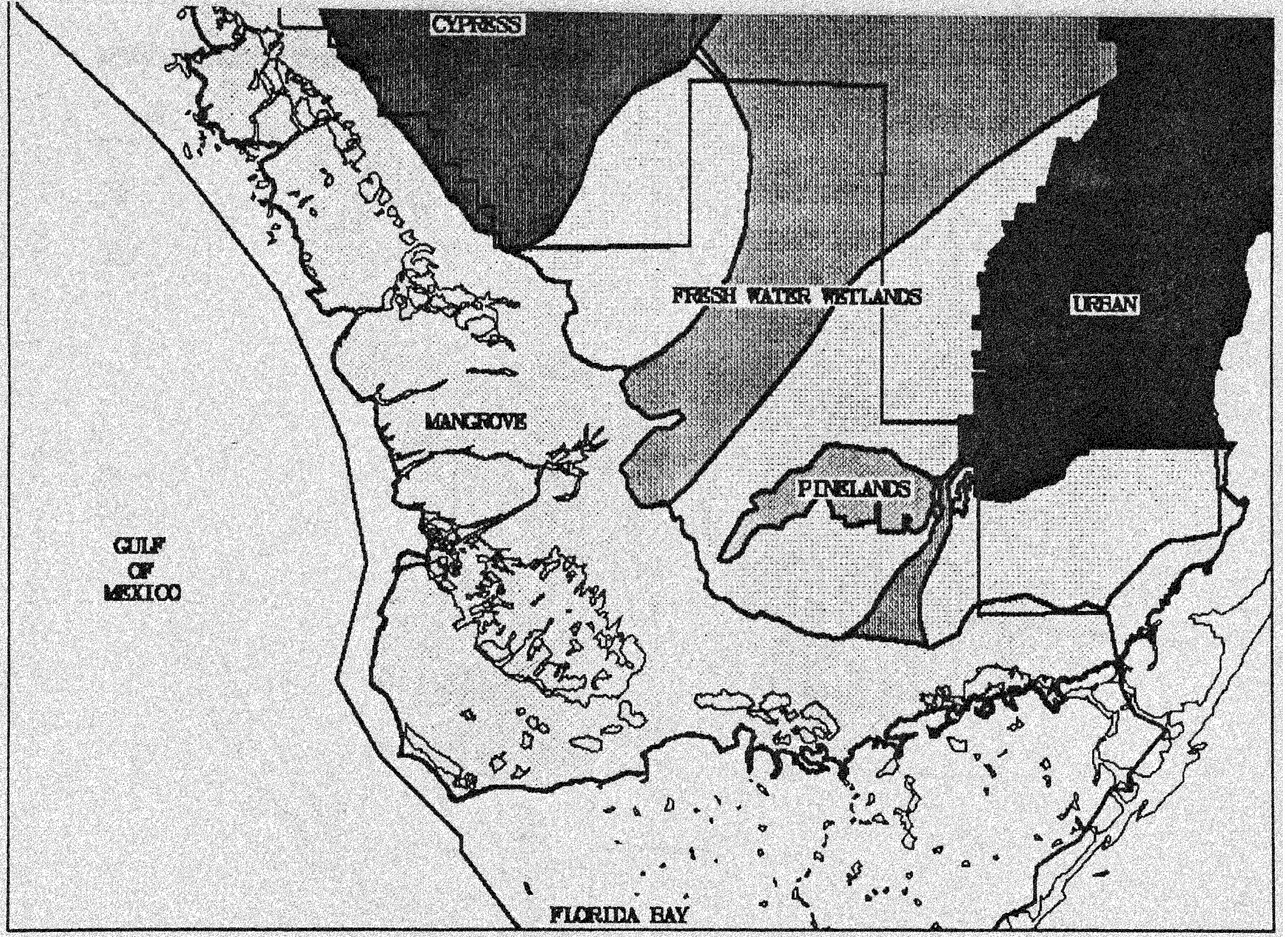

Figure 3. Major habitat types of Everglades National Park. 
Florida Bay keys - These islets, scattered throughout the bay, range in size from a few dozen square meters to hundreds of hectares. They are of three kinds: 1) more than $1 \mathrm{~m}$ of peat soil throughout and covered completely with mangrove forest (found especially in northeast Florida Bay), 2) perimeter of mangrove enclosing a depressed central area, and 3) perimeter of mangrove enclosing a center of higher elevation dominated by grasses. The central area is mostly impervious marl and of sparse vegetation while the perimeter is elevated and hosts a variety of tropical hardwood trees as well as mangroves.

Submarine meadows - Numerous areas deeper than the surrounding mud flats that stay inundated at all times. Usually covered with lush growths of various species of seagrasses (i.e., Thalassia testudinum, Halodule wrightii, Syringodium filiforme).

\section{METHODS AND MATERIAL}

Terminology - Bald Eagle nesting territories are defined as areas of nesting activity where only one pair nests. Territories may include more than one nest, but only one is used per season. The high frequency of observations per season in this study allowed for a more precise terminology than that suggested by Postupalsky (1974). In this study, active territories are those in which an adult is seen at least once during the breeding season. Nesting attempts (Postupalsky's "active nests") are defined as an adult seen on the nest as if incubating or brooding and/or the presence of eggs or young. Nests were considered successful when young birds of fledging size were seen in or near them. Bald eagle nesting seasons in ENP span from fall of one year to spring of the next year. In order to avoid confusion and permit better readability of the text, nesting seasons are referred to by the year in which they start (i.e., the october 1977 to April 1978 season is referred to as the 1977 season).

Aerial surveys - Data were collected using low-level aerial census techniques as described in Fuller and Mosher (1987), Grier (1982b), and Postupalsky 
(1974). A small, fixed-wing aircraft (i.e., Cessna 172 or 182) was flown at low-level $(30-70 \mathrm{~m})$ over all potential Bald Eagle nesting habitat in ENP during each breeding season (October-April). When a nest was located its location was recorded as well as the presence and activity of eagles near the nest. Nests were circled a number of times sufficient to determine their contents and condition. Flights were continued throughout each season at intervals to determine the development and final outcome of nesting attempts (usually 5 or 6 flights). Since many Bald Eagles use their nests for multiple seasons a large proportion were located each year by searching the same sites that were active the year before. By surveying all potential nesting habitat, beginning flights early in the season, and making multiple flights over each area, sampling error (Fraser et al. 1984) and incomplete data (Fraser et al. 1983, Grier et al. 1981) were minimized.

Ground searches - When necessary and feasible, aerial surveys were augmented by ground searches. For the most part, ground searches were carried out on keys that appeared inactive from the air but had a history of active nesting. These keys were visited via small boat and searched on foot for nests. If activity was found, the nest was revisited repeatedly at intervals necessary to determine the development and outcome of the attempt.

Nesting chronology - I reviewed field notes from all aerial surveys and ground checks for seasons 1959 through 1989. For every nesting attempt I listed year, territory number, and Julian date and an activity code of each observation made. Activity codes were as follows: 1) no activity before a nesting attempt (adults may have been present but nest was not built or refurbished), 2) old nest refurbished or new nest built, 3) apparent incubation or eggs present in the nest, 4) chicks in grey down, 5) chicks mostly or fully feathered, 6) young of fledging size, 7) activity at nesting territory after nesting activity is passed, and 8 ) no eagles or activity at territory after nesting. Occasionally eagles in Florida Bay roosted or sat in their nests very early in the season, appearing to be incubating (Robertson pers. comm.). In order to avoid any confusion, if a bird was 
noted as incubating early in the season and subsequently was observed away from the nest then seen incubating again later in the season, I didn't count the first activity as incubation $(n=6)$.

Nest-sites - Nest locations were recorded and mapped. Nest trees were measured for height, diameter at breast height (DBH), height of nest and condition of nest tree (i.e., live, dead). At 12 sites distance and height of the 4 nearest neighboring trees $\geq 2 \mathrm{~m}$ tall were measured. Size of nestkeys were calculated using USGS orthophoto maps.

Database - Field notes were kept on all activity and observations. A computer database was maintained with the following fields: territory name, territory number, season, active $(y / n)$, nesting attempt $(y / n)$, nesting success $(y / n)$, no. of young fledged, maximum no. of adults seen, no. of sub-adults seen, and new nest $(y / n)$. Rainfall data were collected at Flamingo Ranger station, Flamingo, ENP.

Analysis - Analysis included descriptive statistics (Sokal and Rohlf 1981) of all reproduction and nest site parameters described above. Comparisons of reproduction parameters were made between east and west Florida Bay using two-tailed paired t-tests and ANOVA. Linear regression was used to determine trends over time for all parameters and to determine relationships between parameters. Where the data permitted, chronology of reproduction was analyzed and compared between areas and between years. Annual reproductive performance was compared with rainfall to determine effects using linear regression. Effects of nesting failure and/or the use of new nests/sites on subsequent nesting efforts were determined for each territory by use of contingency tables. Longevity of nests and sites (number of years that a particular nest or site existed) were calculated and correlations were computed for each species and condition of nest tree. For all analyses a probability of 0.05 was considered significant. Statistical analyses were performed with the ABstat statistical package (Anderson-Bell Co., 1984) or Krebs (1989). Means are given \pm 2 standard errors. 
Surveys - Aerial surveys and ground checks were conducted each season from 1959 to 1989 except 1984 and 1985. Notes for the 1962 season were not available for analysis. The 1981 survey consisted of only one observation per territory and these data were not included in any of the analyses. Analyses, therefore included data from 26 seasons. During the period of record, the number of territories observed ranged from 27 to 31 and a total of 5528 observations were made (Table 1). Over all years each territory was observed an average of $7.3 \pm 0.682$ times per season (Fig. 5). As part of an analysis of nesting chronology (see below) I compiled the Julian dates of all observations made at territories in which there were nesting attempts for each season of the study period. The distribution of these observations (n $=3674$ ) is shown in figure 6. Each survey included most or all of the territories, therefore, this distribution is indicative of the distribution of all observations combined. Since data on nesting attempts are sensitive to the timing of census flights (Eraser et al. 1983) I performed a regression of total nesting attempts on date of first census flight and found no relationship $\left(\mathrm{x}^{2}=.168\right.$, df $\left.=21, \mathrm{P}=.579\right)$.

Territories - There were 31 historically defined Bald eagle territories in Elorida Bay during the study (Fig. 7). The number of active territories observed ranged from 27 to 31 per season resulting in breeding densities of 1 territory $/ 50 \mathrm{~km}^{2}$ to 1 territory/ $43.5 \mathrm{~km}^{2}$. I did not calculate the areas of territories because I had no data concerning defended home-range or foraging areas. However, distances between active territories and their nearest active neighbors were calculated for use in analysis of distribution. I used Clark and Evan's (in Krebs 1989) plotless method for known population density to analyze the spatial pattern of territories in Florida Bay. Clark and Evan's method results in an index of aggregation ( $R$ ) where: $R=1$, random spatial pattern; $R$ approaches 0, clumping; and, $R$ approaches the upper Iimit of 2.15 , regular spacing. Statistical significance is determined by a zscore; greater than 1.96 indicates a significantly regular pattern. For all seasons combined $R=1.14 \pm 0.192$. For each season, $R$ was above 1.0 (Fig. 8) 
and $z$-scores were above 1.96. Regularity of spatial distribution is indicated by the preponderance of intermediate distances between territories $\left(X^{2}=11.02\right.$, df $\left.=1, \mathrm{P}=0.0009\right)$ (Eig. 9) . 
Table 1. Numbers of observations at Florida Bay Bald Eagle territories.

\begin{tabular}{|c|c|c|c|}
\hline Season & $\begin{array}{l}\text { No. Territories } \\
\text { Observed }\end{array}$ & $\begin{array}{l}\text { Average } \\
\text { Observations/ } \\
\text { Territory }\end{array}$ & Standard Error \\
\hline 1959 & 27 & 6.52 & 0.761 \\
\hline 1960 & 27 & 6.30 & 0.295 \\
\hline 1961 & 27 & 4.92 & 0.156 \\
\hline 1963 & 27 & 6.52 & 0.403 \\
\hline 1964 & 27 & 8.33 & 0.347 \\
\hline 1965 & 27 & 9.55 & 0.429 \\
\hline 1966 & 28 & 7.14 & 0.322 \\
\hline 1967 & 28 & 8.57 & 0.414 \\
\hline 1968 & 28 & 7.71 & 0.302 \\
\hline 1969 & 28 & 5.82 & 0.160 \\
\hline 1970 & 28 & 4.68 & 0.169 \\
\hline 1971 & 29 & 7.27 & 0.145 \\
\hline 1972 & 29 & 9.31 & 0.342 \\
\hline 1973 & 29 & 8.86 & 0.344 \\
\hline 1974 & 30 & 9.90 & 0.259 \\
\hline 1975 & 30 & 9.23 & 0.204 \\
\hline 1976 & 31 & 6.35 & 0.207 \\
\hline 1977 & 31 & 6.48 & 0.273 \\
\hline 1978 & 30 & 6.83 & 0.068 \\
\hline 1979 & 30 & 6.76 & 0.122 \\
\hline 1982 & 29 & 7.62 & 0.185 \\
\hline 1983 & 31 & 10.96 & 0.483 \\
\hline 1986 & 31 & 7.03 & 0.173 \\
\hline 1987 & 31 & 5.90 & 0.251 \\
\hline 1988 & 31 & 8.29 & 0.274 \\
\hline 1989 & 31 & 3.35 & 0.239 \\
\hline mean \pm 2 S.E. & $29.03 \pm 0.612$ & $7.31 \pm 0.682$ & \\
\hline
\end{tabular}




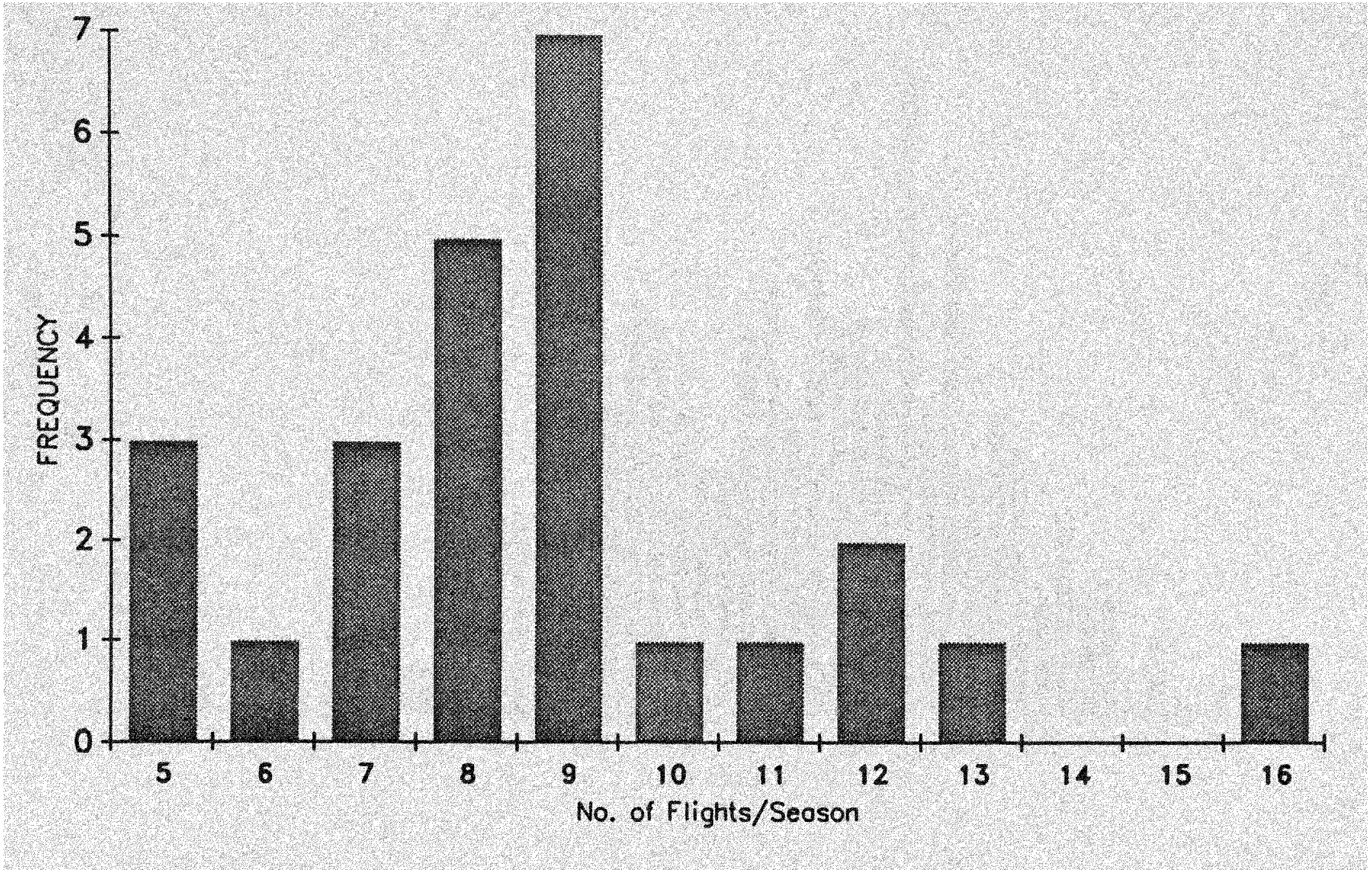

Figure 5. Frequency distribution of numbers of census flights per Bald Eagle breeding season at Florida Bay, $1959-1989$. 


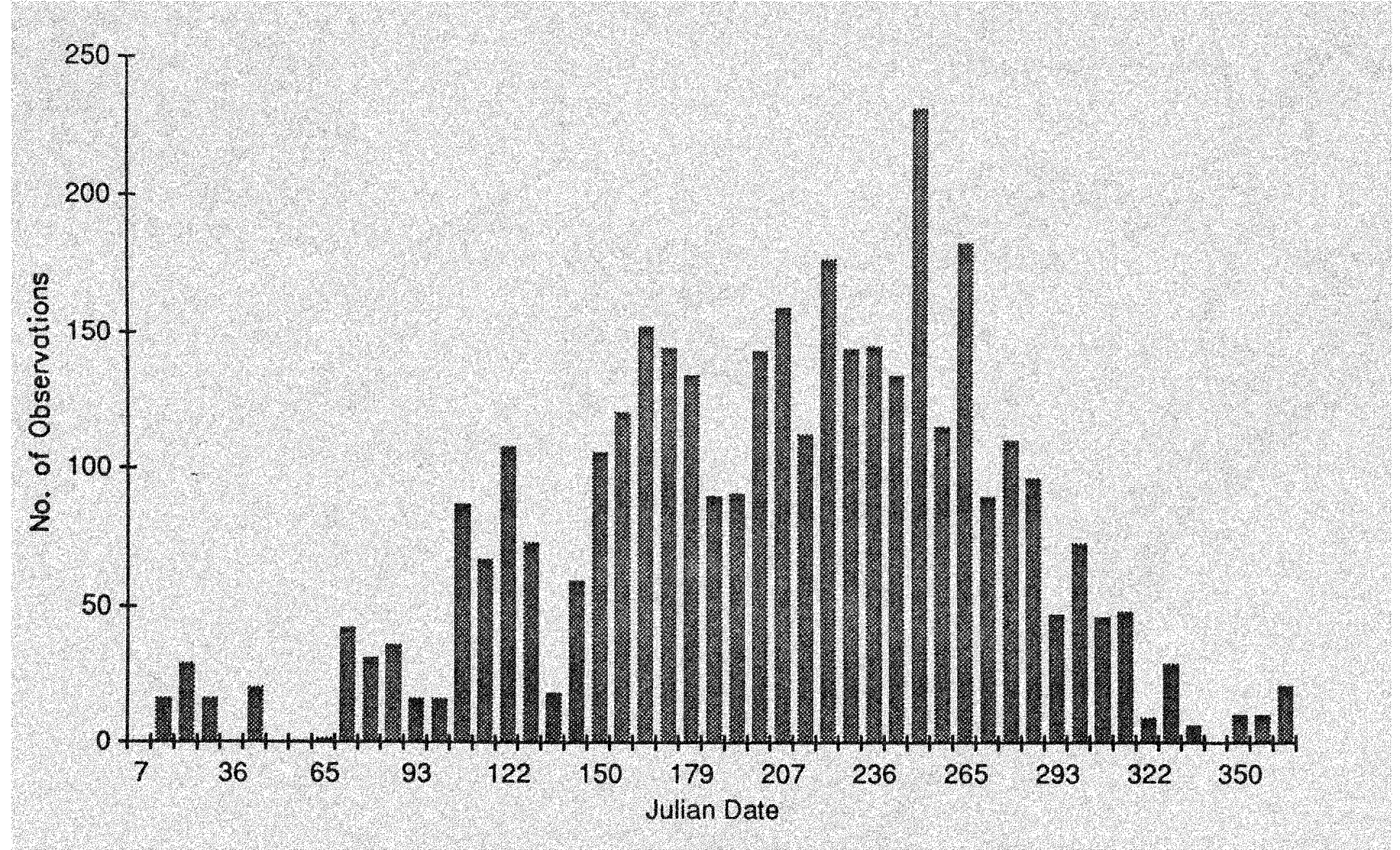

Eigure 6. The distribution of 3674 observations of Florida Bay Bald Eagle territories in which there were nesting attempts, $1959-1989$. 


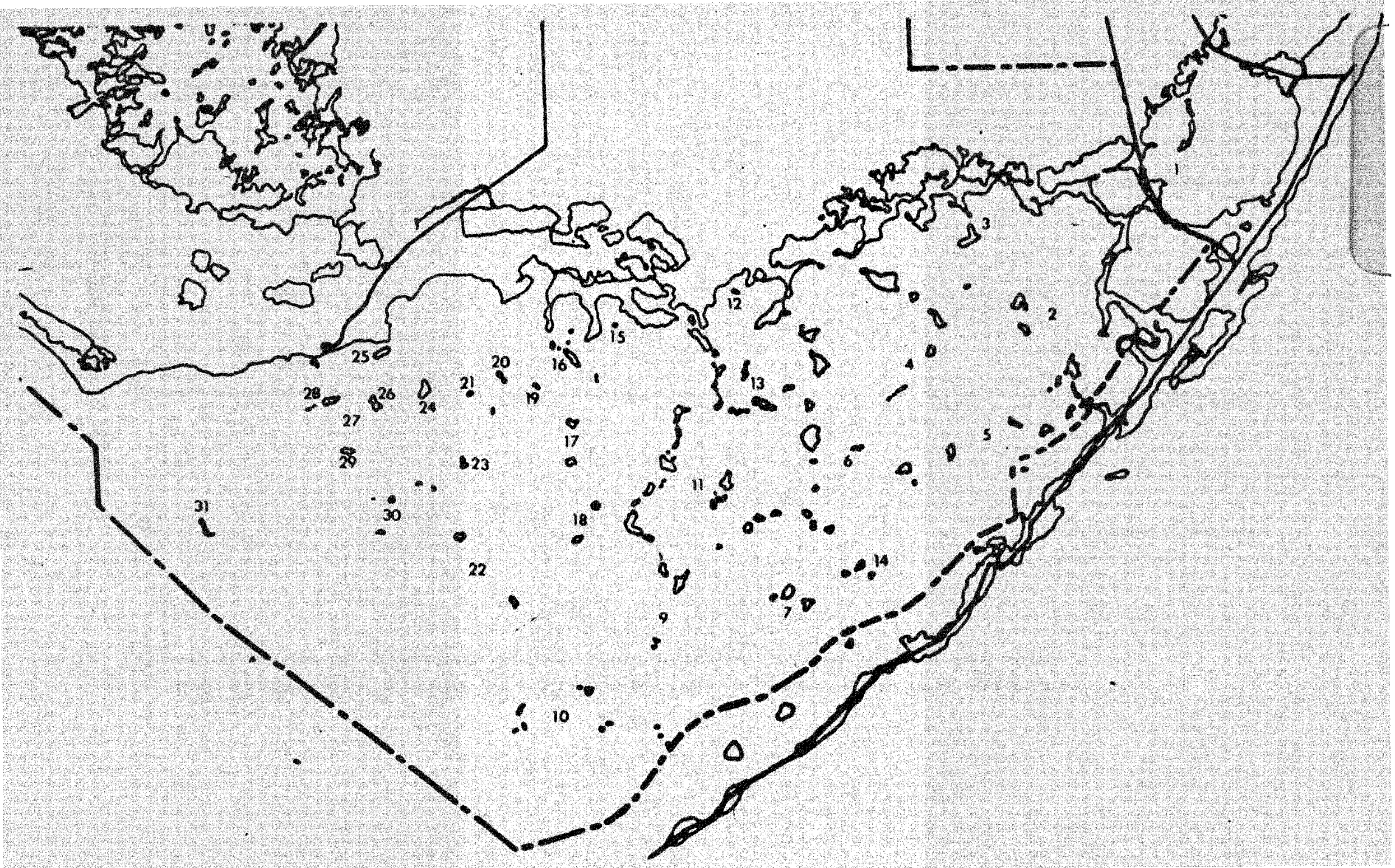

Figure 7. Thirty-one historically defined Bald Eagle breeding territories in Florida Bay, 1959 - 1989. The dashed line indicates the boundary between eastern and western Florida Bay. 


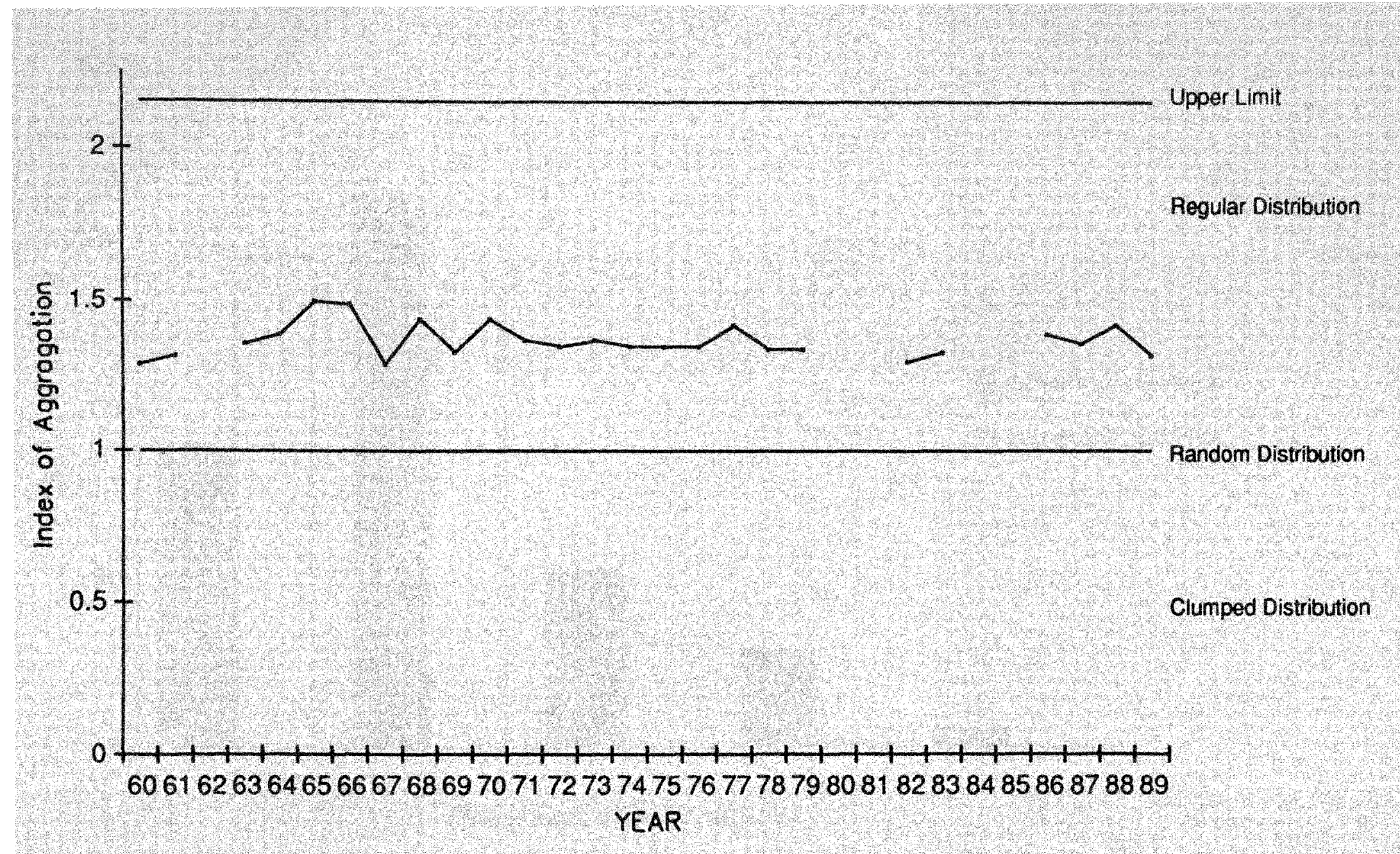

Figure 8. Index of aggragation (Clark and Evans in Krebs 1989) for active Bald Eagle territories in Florida Bay, 1959 - 1989. The values for each year were well above 1.0 , indicating a significant regularity in the spacing of territories. 


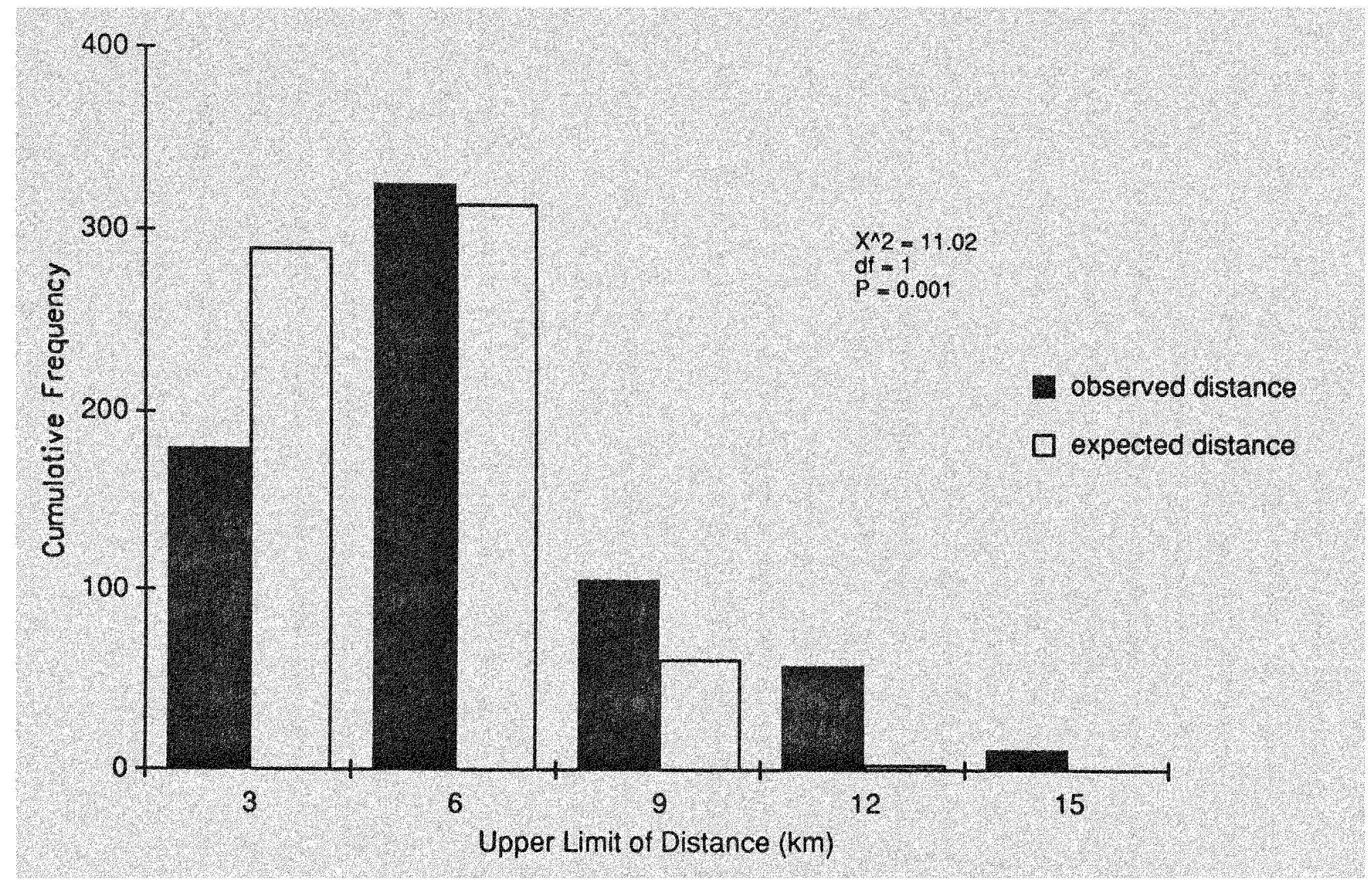

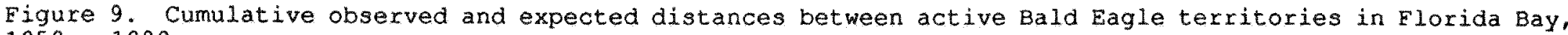
1959 - 1989. 


\section{Reproduction}

Nesting chronology - Bald Eagles in Florida Bay were observed with new or repaired nests as early as 7 August, and were incubating as early as 15 october. Young of fledging size have been at nests as late as 25 May (Fig. 10). Table 2 shows nesting chronology in Florida Bay for the period of record. Incubation was earlier in the western half of Florida Bay (mean = 189.2) than in the eastern half (mean $=194.6)(t=2.84$, df $=890, P=$ 0.002 ) as was the presence of downy chicks (western mean $=221.72$, eastern mean $=229.2, t=3.80, \mathrm{df}=418, \mathrm{P}=0.0001)$. Post-nesting activity at the nesting territories continued later in the season in the western half (western mean $=272.1$, eastern mean $=261.9, t=2.56$, df $=424, P=.005$ ) (Fig. 11). Successful attempts began earlier and were active later than unsuccessful attempts (Table 3 and Fig. 12). I calculated the effect of rain on timing of nesting by correlating the mean date of incubation of each season with the sum of rainfall (in inches) recorded at Flamingo Ranger Station from 1 July to the overall mean date of incubation ( 7 January), there was no significant relationship $(F=0.525$, df $=25, P=0.475)$.

Population - Total nesting Bald Eagles (defined as $2 \times$ nesting attempts) in Florida Bay ranged 32 to 50 (mean $=41.8 \pm 2.21$ ) and total nonnesting adults (the number of adult eagles seen on territories where no nesting attempt occurred) ranged from 2 to 22 (mean $=11.3 \pm 2.04$ ). The overall adult Bald Eagle population ranged from 40 to 59 with a mean of $53.2 \pm 1.84$ (Fig. 13). Subadult Bald Eagles do not maintain territories as adults do. I assumed that the occurrence of subadults during aerial surveys was a random event and that the number of subadults encountered was proportional to the subadult population present. Therefore, instead of using total numbers of subadults observed, I calculated the number of subadults observed per hour of observation for each year (Fig. 14). This ranged from 0.08 to 1.53 (mean= $0.57 \pm 0.164)$. 
Table 2. Summary statistics of the chronology of nesting by Bald Eagles in Florida Bay, 1959 - 1989.

\begin{tabular}{|c|c|c|c|c|c|c|c|}
\hline Activity & $\begin{array}{l}\text { Sample } \\
\text { Size }\end{array}$ & $\begin{array}{l}\text { Mean } \\
\text { Date }\end{array}$ & Julian & $\begin{array}{l}\text { Standard } \\
\text { Error }\end{array}$ & Min. & $\operatorname{Max}$. & Range \\
\hline $\begin{array}{l}\text { Pre-nesting } \\
\text { inactive }\end{array}$ & 725 & 110 & $\left(\begin{array}{ll}18 & \text { oct }\end{array}\right)$ & 1.61 & 8 & 238 & 230 \\
\hline Nest repaired & 306 & 152 & (29 Nov) & 1.68 & 38 & 234 & 196 \\
\hline Incubation/Eggs & 895 & 191 & (7 Jan) & 0.95 & 107 & 286 & 179 \\
\hline Chicks - Downy & 421 & 225 & (10 Eeb) & 1.00 & 167 & 314 & 147 \\
\hline $\begin{array}{l}\text { Chicks - } \\
\text { Feathered }\end{array}$ & 306 & 249 & ( 6 Mar) & 0.98 & 202 & 306 & 104 \\
\hline $\begin{array}{l}\text { Fledging sized } \\
\text { young }\end{array}$ & 228 & 269 & (26 Mar) & 1.25 & 219 & 329 & 110 \\
\hline $\begin{array}{l}\text { Post-nesting } \\
\text { active }\end{array}$ & 427 & 266 & (23 Mar) & 1.99 & 171 & 365 & 194 \\
\hline $\begin{array}{l}\text { Post-nesting } \\
\text { inactive }\end{array}$ & 366 & 273 & (30 Mar) & 1.99 & 174 & 365 & 191 \\
\hline
\end{tabular}


Table 3. Comparisons of the chronology of nesting activity between successful and unsuccessful Bald Eagle nesting attempts in Florida bay, 1959 - 1989, using independent $t$-tests.

\begin{tabular}{|c|c|c|c|c|c|c|}
\hline Activity & & $\begin{array}{l}\text { Mean } \\
\text { Date }\end{array}$ & $\begin{array}{l}\text { Standard } \\
\text { dev. }\end{array}$ & $\begin{array}{l}t- \\
\text { value }\end{array}$ & DE & P \\
\hline \multirow{2}{*}{$\begin{array}{l}\text { Pre-nesting, } \\
\text { inactive }\end{array}$} & success & 106.8 & 45.06 & 2.32 & 722 & $0.010 * *$ \\
\hline & unsuccess & 114.3 & 41.5 & & & \\
\hline \multirow[t]{2}{*}{ Nest Repair } & success & 148.3 & 25.66 & 2.73 & 306 & $0.003 * \star$ \\
\hline & unsuccess & 157.5 & 32.6 & & & \\
\hline \multirow[t]{2}{*}{ Incubation/Eggs } & success & 187.1 & 24.92 & 4.99 & 890 & $0.000 * \pi *$ \\
\hline & unsuccess & 196.6 & 31.2 & & & \\
\hline \multirow[t]{2}{*}{ Chicks - Downy } & success & 224.9 & 18.57 & 0.68 & 418 & 0.247 \\
\hline & unsuccess & 226.2 & 22.3 & & & \\
\hline \multirow{2}{*}{$\begin{array}{l}\text { Chicks - } \\
\text { Eeathered }\end{array}$} & success & 248.7 & 16.52 & 1.12 & 304 & 0.130 \\
\hline & unsuccess & 251.0 & 18.03 & & & \\
\hline \multirow{2}{*}{$\begin{array}{l}\text { Post-nesting, } \\
\text { active }\end{array}$} & success & 282.3 & 39.67 & 8.26 & 424 & $0.000 * \star *$ \\
\hline & unsuccess & 251.6 & 36.86 & & & \\
\hline \multirow{2}{*}{$\begin{array}{l}\text { Post-nesting, } \\
\text { inactive }\end{array}$} & success & 281.8 & 38.73 & 4.51 & 364 & $0.000 * * *$ \\
\hline & unsuccess & 264.2 & 35.62 & & & \\
\hline
\end{tabular}



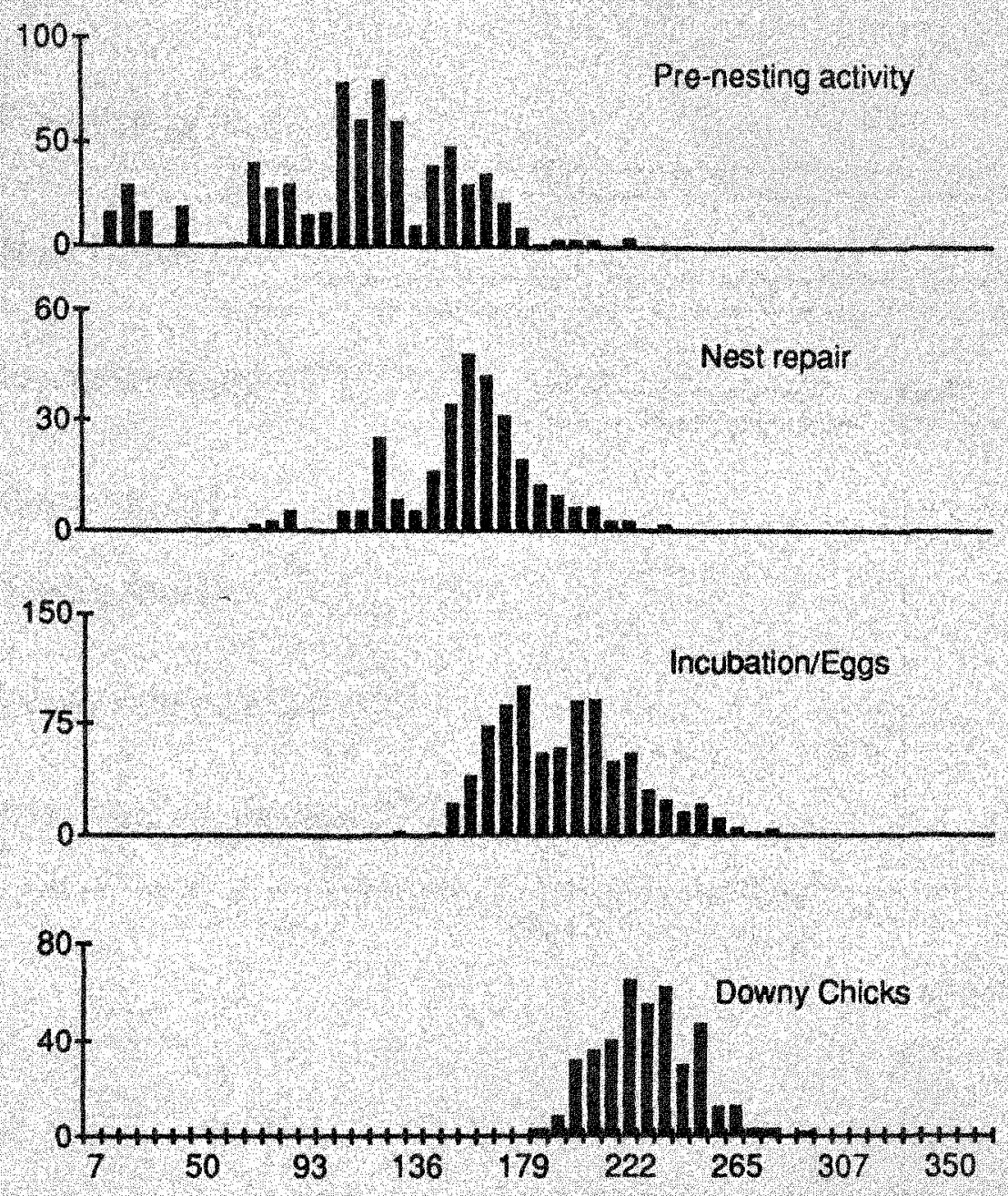
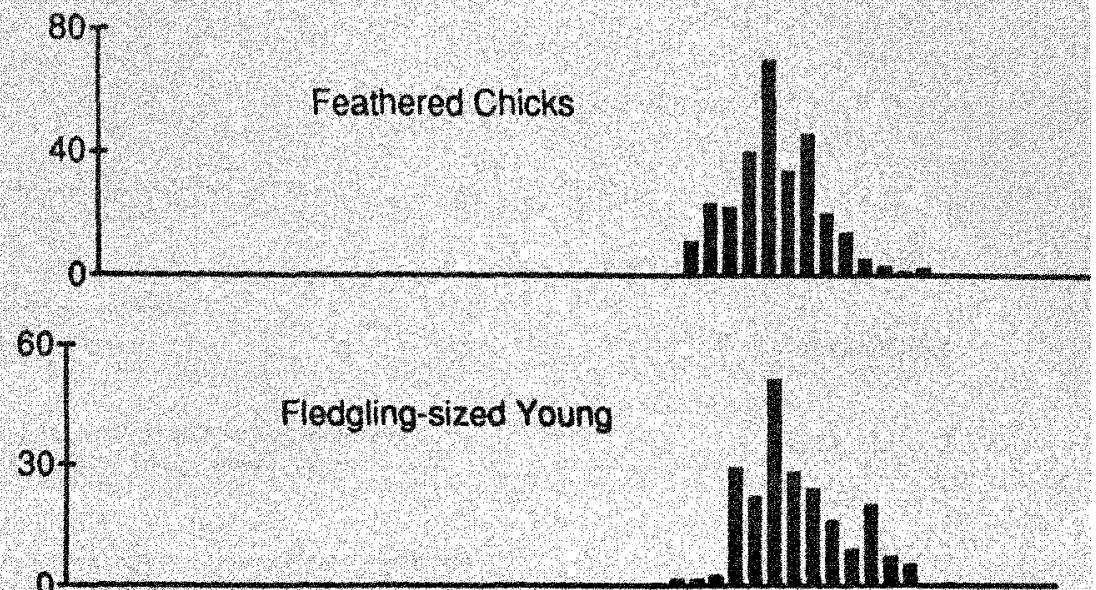

Fledgling-sized Young
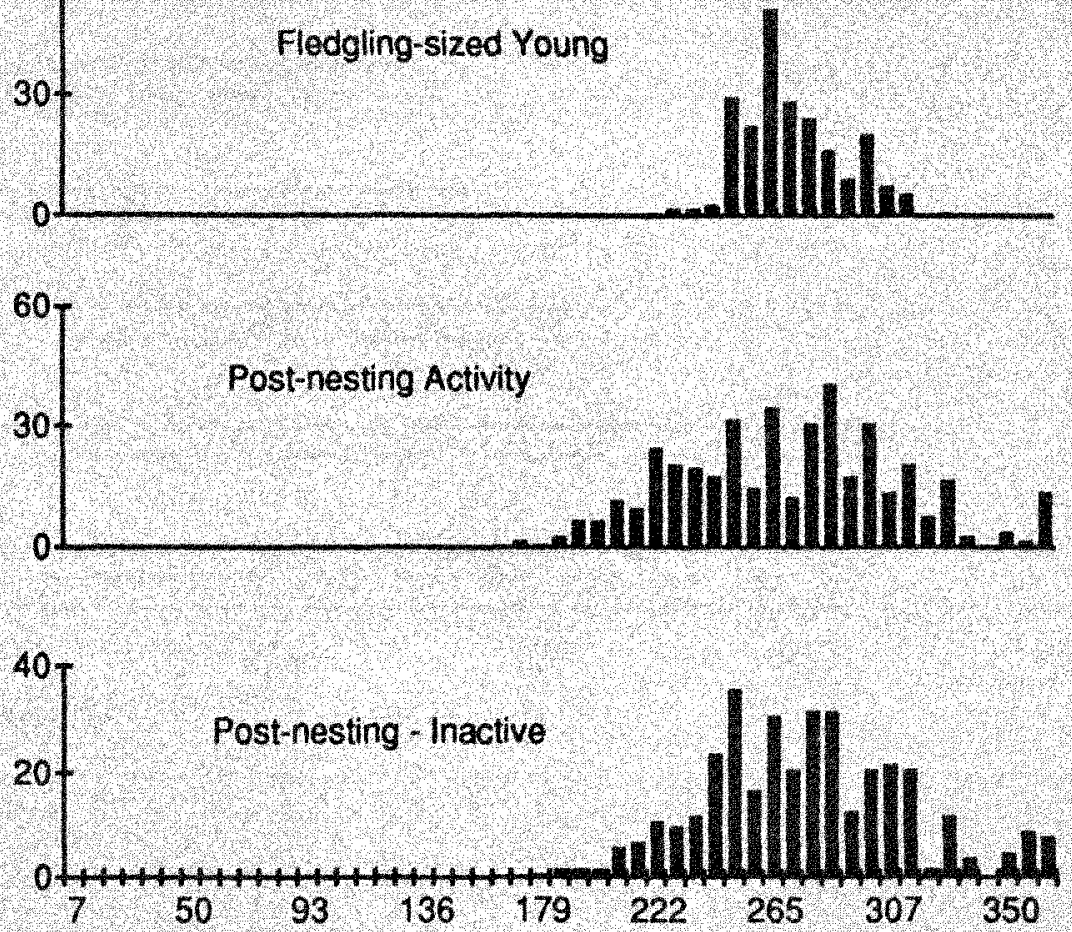


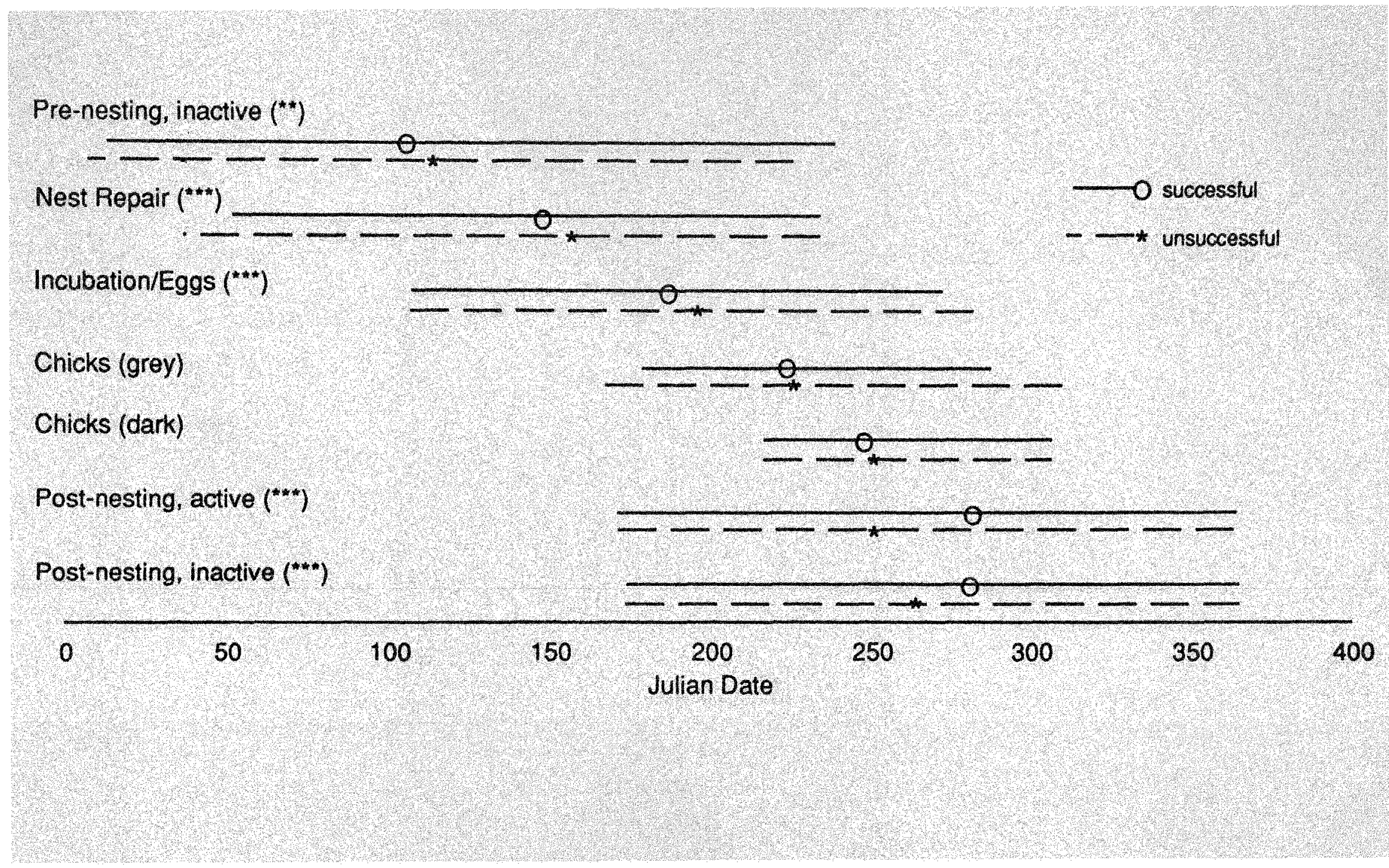

Figure 11. Means and ranges of seven stages of Bald Eagle nesting activity in Florida Bay for successful and unsuccessful nesting attempts. Results of $t$-test in text, $* *=$ significant at $P<0.01$ level, $\star \star \star=$ significant at $P<0.001$ level. 


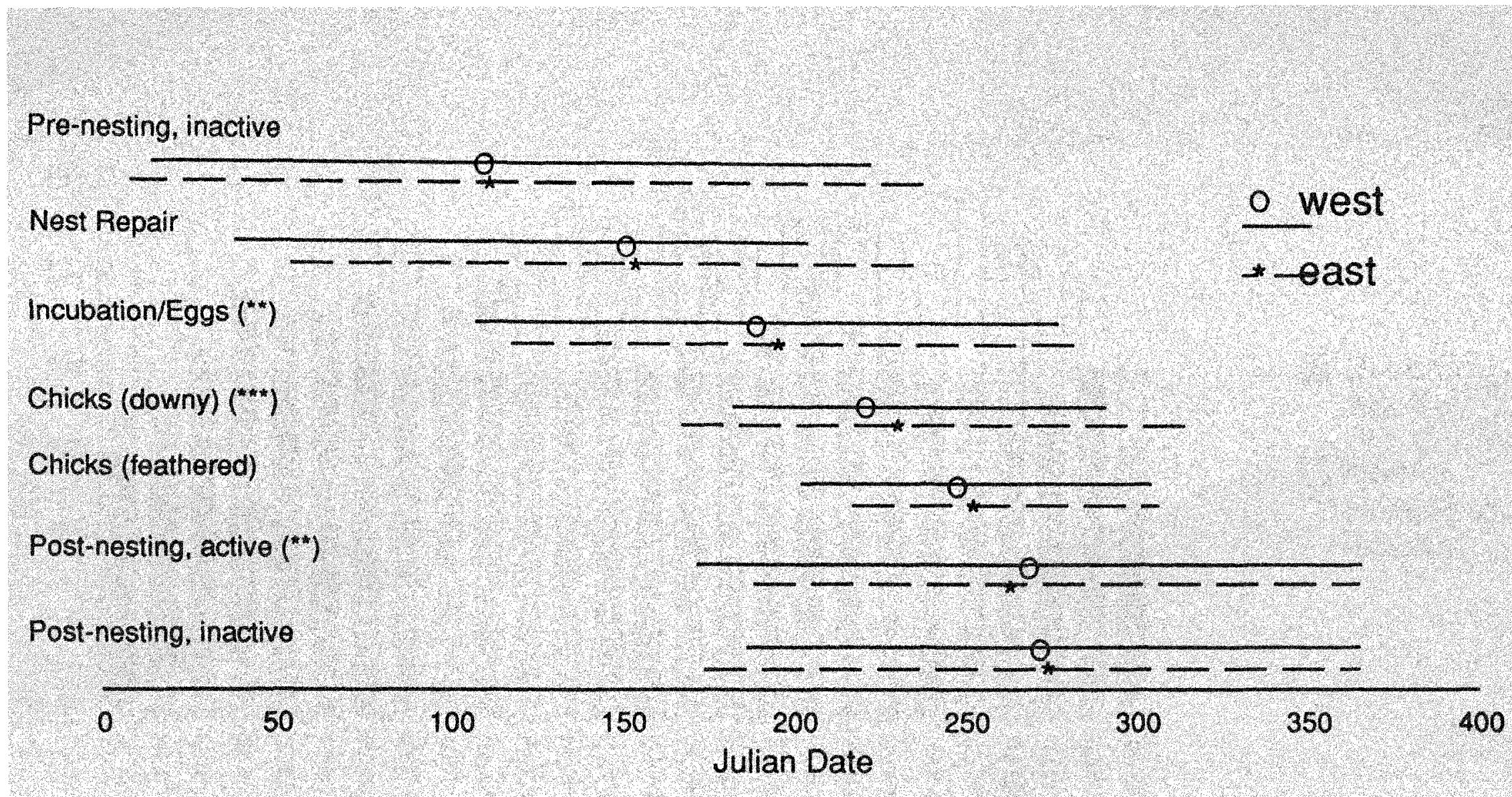

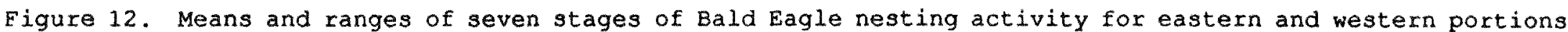
of Florida Bay. Results of t-test in text, $* *=$ significant at $P<0.01$ level, $* \star *=s i g n i f i c a n t$ at $P<0.001$ level. 


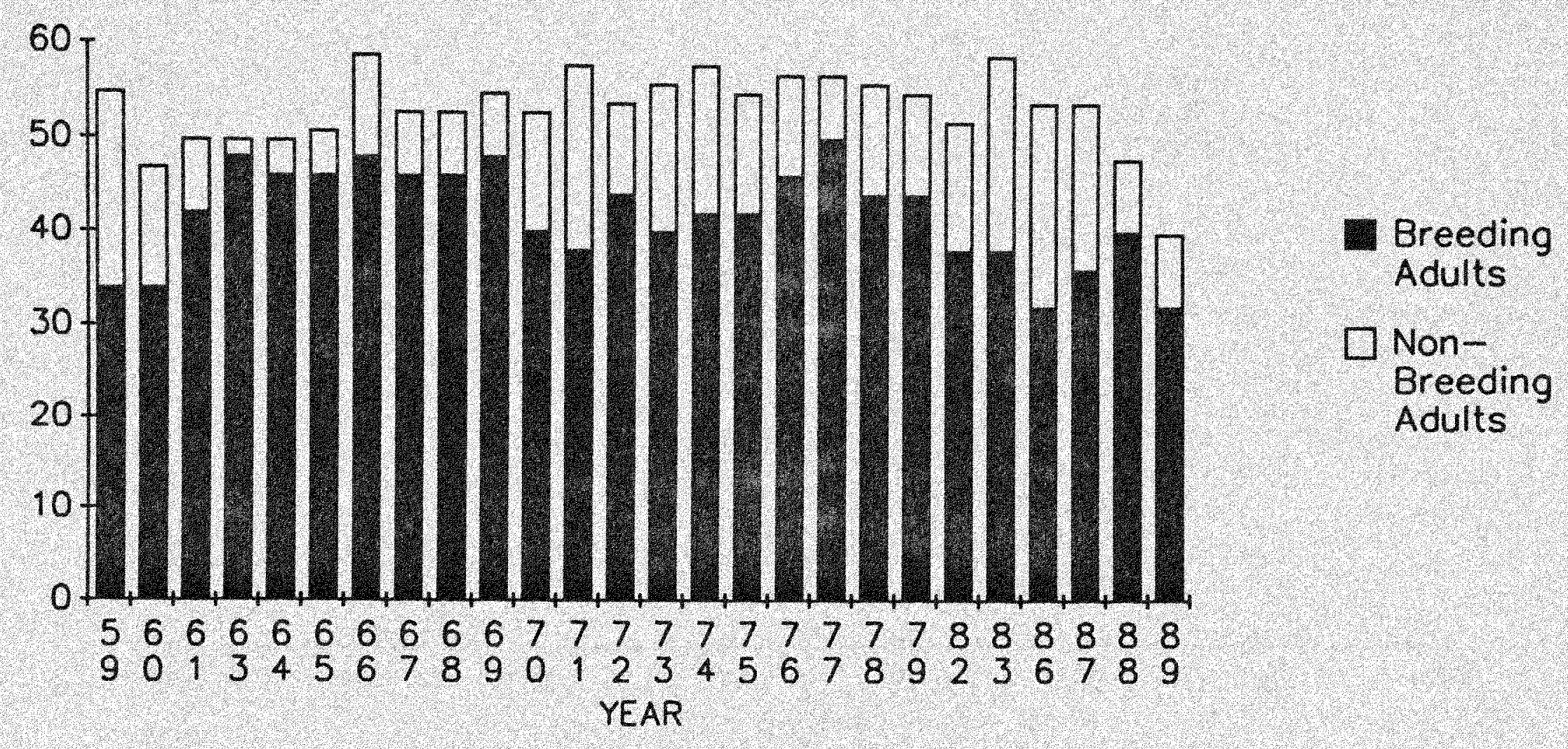

Figure 13. Breeding and nonbreeding adult Bald Eagle populations of Florida Bay, Everglades National Park, 1959 - 1989. 


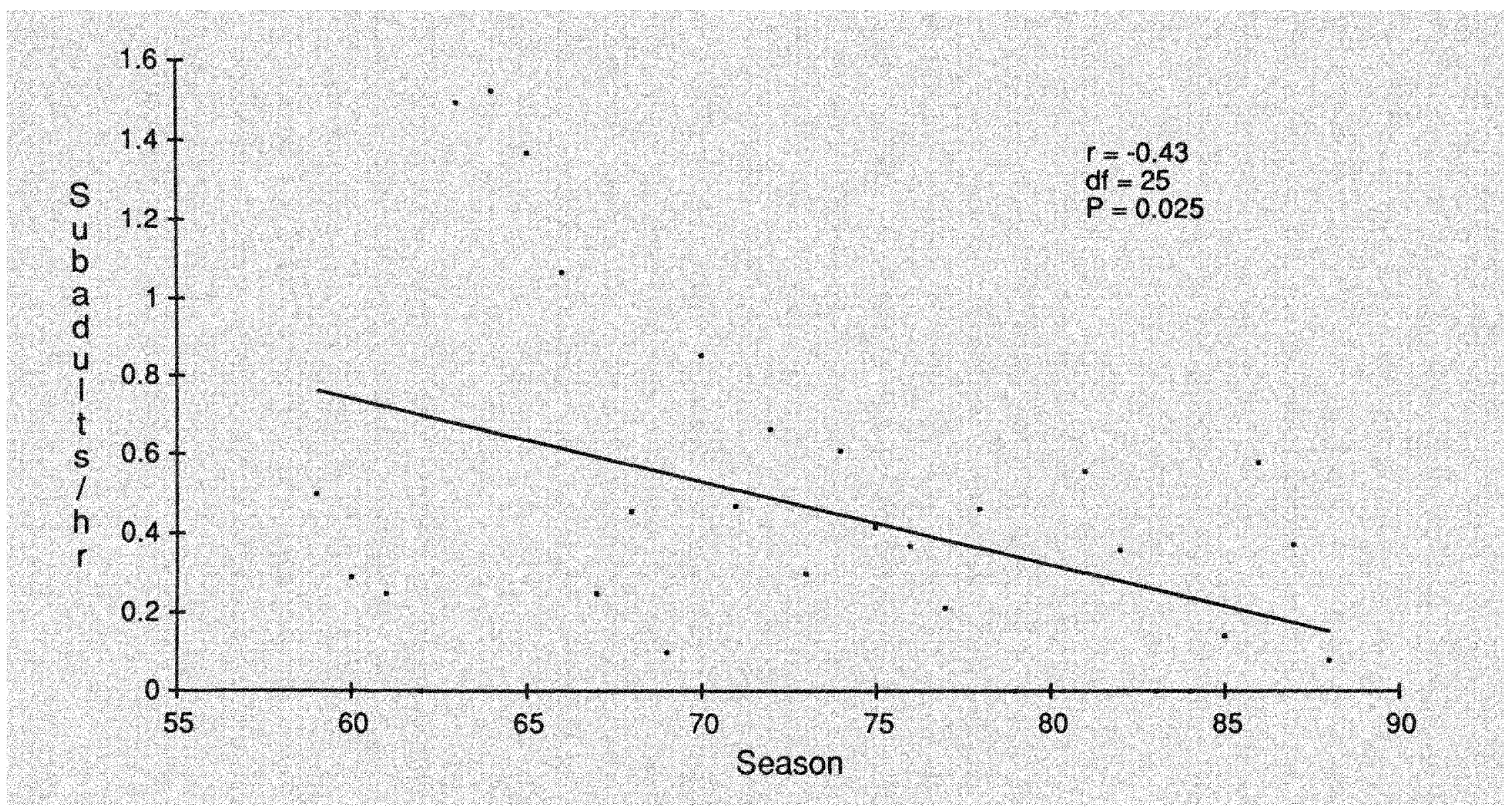

Eigure 14. Number of subadult Bald Eagles observed per hour of aerial census in Florida Bay, 1959 - 1989. 
Over the time of the study, the number of nesting attempts (and therefore the number of nesting adults) showed a slight downward trend but this was not significant $(x=-.327, d f=25, P=0.10)$. The number of nonnesting adults showed a slight but significant increase $(x=0.43$, df $=25, P=0.02)$. Overall numbers of adults showed no trend over the period of the study (r $=$ $0.08)$. Subadults observed per hour of survey showed a marked decIine over years $(r=-0.43$, df $=25, P=0.025 ;$ Fig. 14).

Production - Most of the known Bald Eagle territories in Florida Bay were active throughout the study period (mean $=95.68 \% \pm 1.584$ ) (Eig. 15). Activity of individual territories (seasons active/seasons observed) ranged from $40 \circ(n=1)$ to $100 \%(n=17)$. A total of 493 young were produced in the 31 territories during the 26 seasons of the study with a mean of $18.9 \pm 1.64$ per season. Brood size averaged $0.85 \pm 0.05$ fledged for all active territories, $0.90 \pm 0.084$ for all nesting attempts and $1.44 \pm 0.054$ for successful nests only (Table 4 and Fig.16). Active Bald Eagle territories were observed 718 times, of which 544 attempted nesting and 345 produced young. Table 4 lists seasonal averages of nesting parameters observed in Florida Bay and Table 5 lists production by 5 -season blocks. These parameters compare favorably with Bald Eagle production found in other studies (Fig. 17).

There were no differences in reproductive effort or success between eastern and western portions of Florida Bay (ANOVA, df $=30$ : active terr. $F=3.201$, $\mathrm{P}=.084$; nest. attempt $\mathrm{F}=0.929, \mathrm{P}=.34 ;$ nest success $\mathrm{F}=0.023, \mathrm{P}=.88$; young fledged $F=0.131, P=.72)$. Nor were their any differences in ratios of reproductive effort (ANOVA, df $=30$ : attempts/active terr. $F=0.39, P=$ .53; nest success/attempt $F=0.48, \mathrm{P}=.49$; fledglings/ attempt $\mathrm{F}=3.58, \mathrm{P}$ $=.068$; and fledglings/nest success $\mathrm{F}=2.36, \mathrm{P}=.135$ ) . 
Table 4. Bald Eagle reproduction in Florida Bay, $1959-1989$ ( $n=26)$.

\begin{tabular}{lll}
\hline $\begin{array}{l}\text { Reproductive } \\
\text { Activity/Season }\end{array}$ & Mean $\pm 2 \mathrm{S.E}$. & Range \\
\hline Active Territories & $27.9 \pm 0.64$ & $25-31$ \\
Nesting Attempts & $21.1 \pm 1.92$ & $16-25$ \\
Successful Nests & $13.1 \pm 0.98$ & $9-18$ \\
Young Fledged & $18.9 \pm 1.61$ & $13-29$ \\
Fledged/Active Terr. & $0.68 \pm 0.052$ & $0.46-1.00$ \\
Fledged/Attempt & $0.90 \pm 0.068$ & $0.61-1.25$ \\
Fledged/Success & $1.44 \pm 0.054$ & $1.18-1.71$ \\
\hline \hline
\end{tabular}




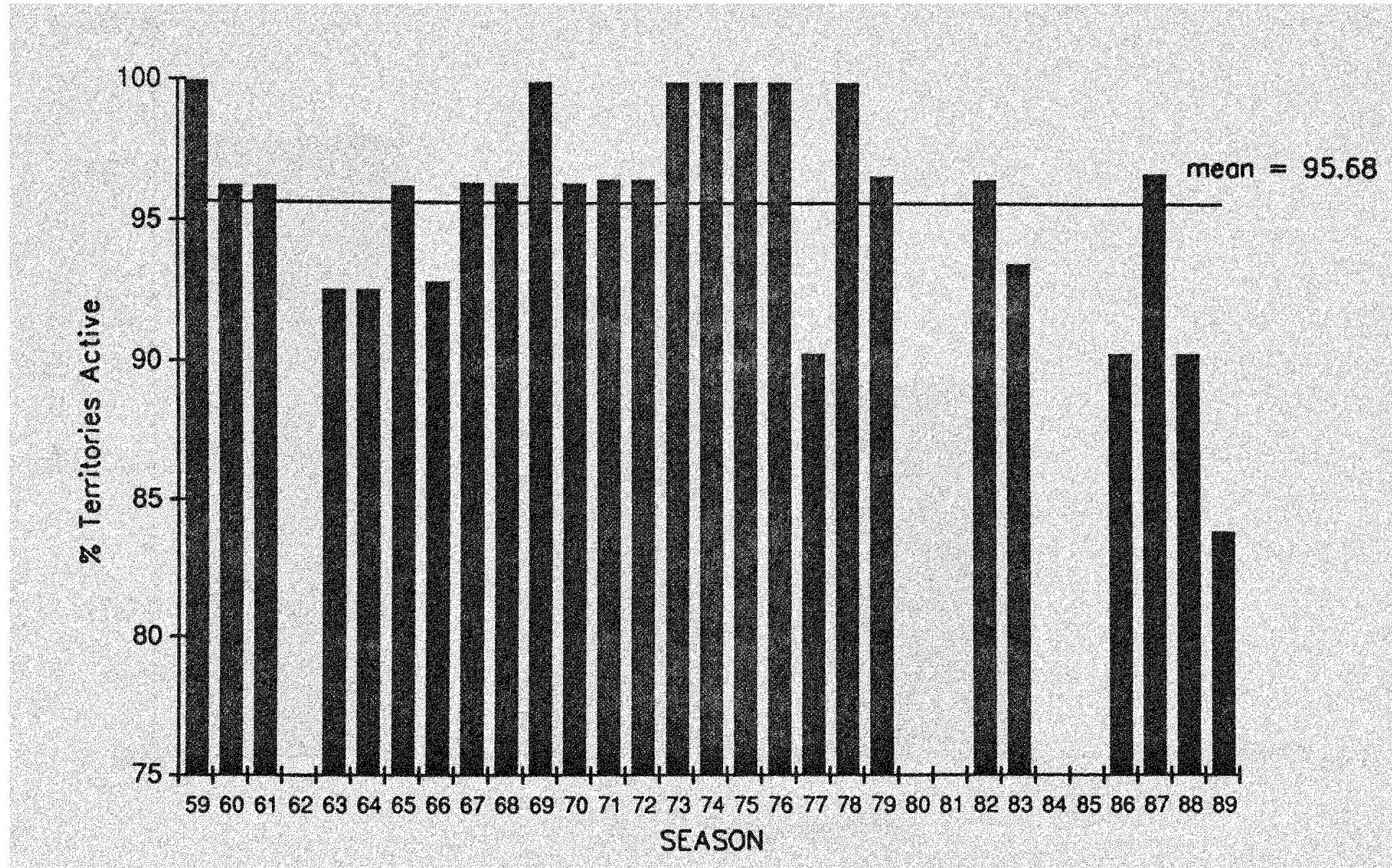

Figure 15. Percent of observed Bald Eagle territories in Elorida Bay that were active, 1959 - 1989. 


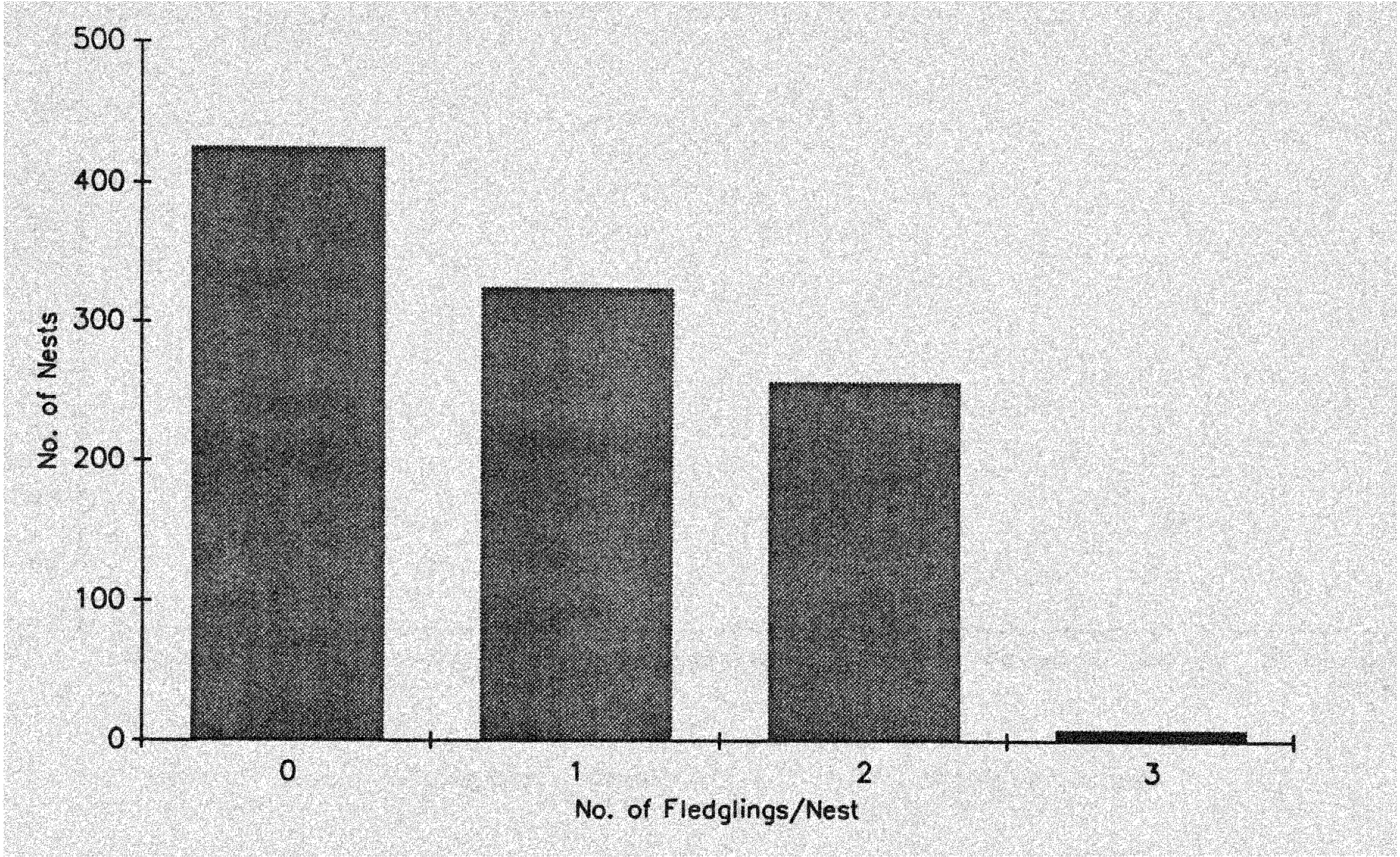

Figure 16. Frequency distribution of the number of Bald Eagle fledglings produced at active nests in Florida Bay, 1959 - 1989. 


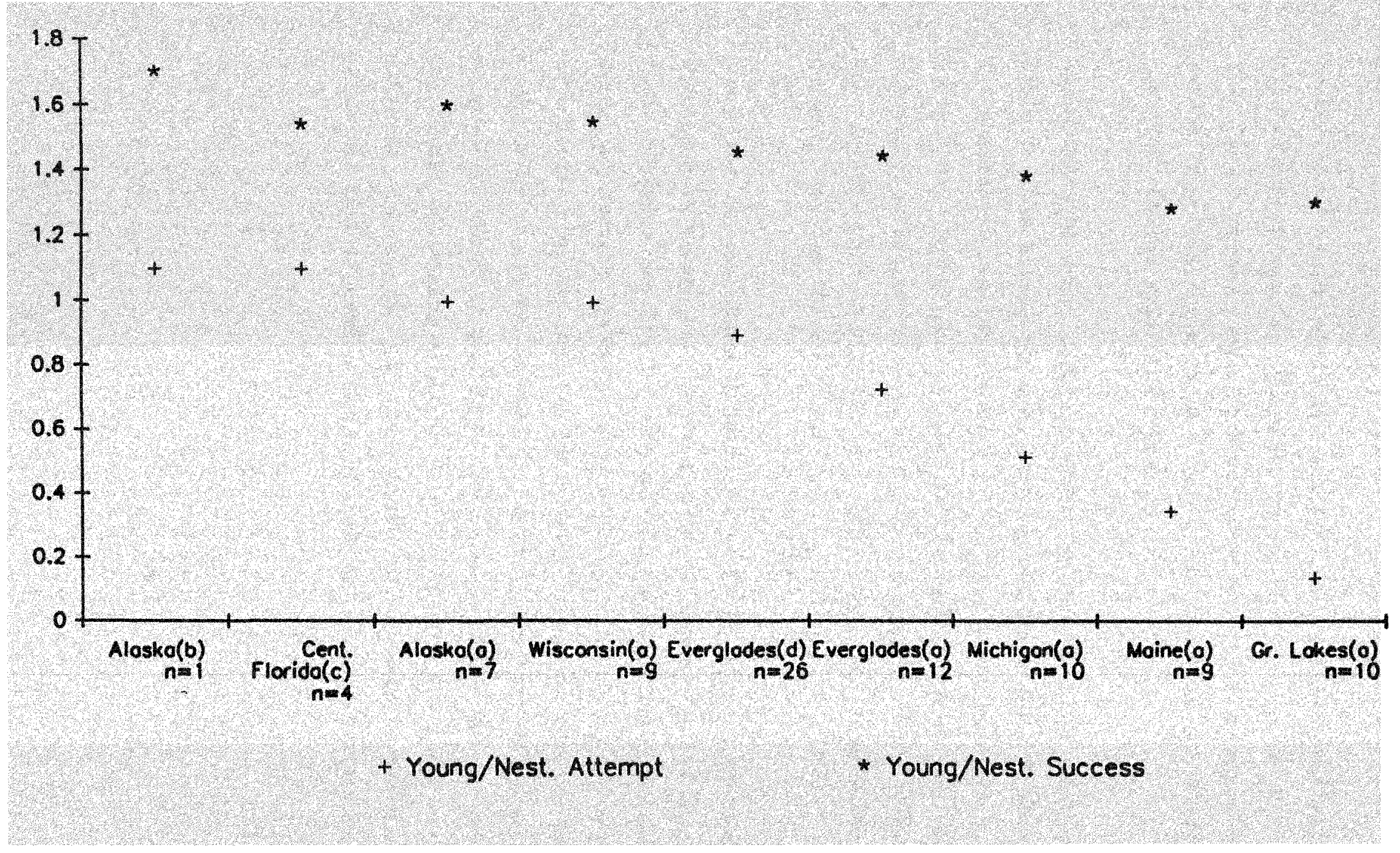

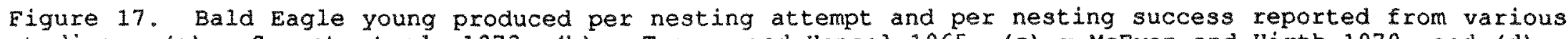

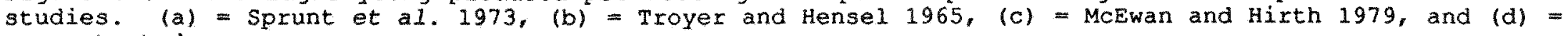
current study. 
As mentioned above, there was a slight but insignificant downward trend in the number of nesting attempts per season in Florida Bay. There was a significant upward trend in the number of active territories observed per season $(\mathrm{I}=0.48, \mathrm{~d} f=25, \mathrm{P}=0.01)$, but all other parameters measured did not show changes over time (Table 6).

The effects of adult population size on reproductive activity are shown in Table 7. The strong correlations between the number of nesting adults and the numbers of nesting attempts $(r=1.00)$, successes $(r=0.56)$, and young fledged $(r=0.50)$ are inherent in the definition of the terms. However, non-nesting adults showed a strong positive correlation with active territories $(x=0.51)$ and a strong negative correlation with nesting attempts $(x=-0.65)($ Fig. 18$)$.

There was no relationship between the level of reproductive activity and success rate except for the data shown in figures 19 and 20 . The number of young produced per nesting attempt has no significant relationship to the number of nesting attempts $(x=-0.18, d f=25, P=0.37$; i.e., no density dependence; Fig. 19), but was positively correlated with the number of active territories $(r=0.38, d f=25, P=0.05)$. The same held true for the number of young produced at successful nests where there was no relationship with the number of nesting attempts ( $r=0.003, d f=25, P=0.98)$ or successful nests $(x=0.01$, df $=25, P=0.93)$ but a positive correlation with the number of active territories $(r=0.47$, df $=25, P=0.01 ; \mathrm{Fig} .20)$. 
Table 5. Bald Eagle reproduction in Elorida Bay, $1959-1989$, by roughly 5-year intervals.

\begin{tabular}{|c|c|c|c|c|c|c|c|c|c|c|c|}
\hline \multirow[b]{2}{*}{ Years } & \multirow{2}{*}{$\begin{array}{l}\text { Active } \\
\text { Terr.s }\end{array}$} & \multirow{2}{*}{$\begin{array}{l}\text { Nest. } \\
\text { Attempts }\end{array}$} & \multirow{2}{*}{$\begin{array}{l}\text { Nests } \\
\text { Succ. }\end{array}$} & \multirow{2}{*}{$\begin{array}{l}\text { \% Att. } \\
\text { Succ }\end{array}$} & \multicolumn{4}{|c|}{$\begin{array}{l}\text { Distribution of young } \\
\text { fledged }\end{array}$} & \multirow{2}{*}{$\begin{array}{l}\text { Tot. } \\
\text { Eledged }\end{array}$} & \multirow{2}{*}{$\begin{array}{l}\text { Eledge/ } \\
\text { succ }\end{array}$} & \multirow{2}{*}{$\begin{array}{l}\text { Eledge/ } \\
\text { att. }\end{array}$} \\
\hline & & & & & 0 & 1 & 2 & 3 & & & \\
\hline $\begin{array}{l}1959- \\
1964\end{array}$ & 121 & 103 & 63 & 61.2 & 59 & 48 & 29 & 1 & 109 & 1.73 & 1.06 \\
\hline $\begin{array}{l}1965- \\
1969\end{array}$ & 135 & 118 & 76 & 64.4 & 41 & 46 & 28 & 0 & 102 & 1.34 & 0.86 \\
\hline $\begin{array}{l}1970- \\
1974\end{array}$ & 142 & 102 & 57 & 55.9 & 50 & 32 & 25 & 0 & 82 & 1.44 & 0.80 \\
\hline $\begin{array}{l}1975- \\
1979\end{array}$ & 149 & 114 & 73 & 64.0 & 42 & 35 & 33 & 3 & 110 & 1.51 & 0.96 \\
\hline $\begin{array}{l}1983- \\
1989 \\
\end{array}$ & 169 & 111 & 71 & 63.9 & 28 & 31 & 31 & 0 & 93 & 1.31 & 0.84 \\
\hline Total & 716 & 548 & 340 & & 220 & 192 & 146 & 4 & 496 & & \\
\hline mean & $\begin{array}{l}143.2 \pm \\
14.202\end{array}$ & $\begin{array}{l}109.6 \pm \\
5.558\end{array}$ & $\begin{array}{l}68.0 \pm \\
6.248\end{array}$ & $\begin{array}{l}61.9 \pm \\
2.860\end{array}$ & & & & & $\begin{array}{l}99.2 \pm \\
9.420\end{array}$ & $\begin{array}{l}1.46 \pm \\
0.446\end{array}$ & $\begin{array}{l}0.90 \pm \\
0.084\end{array}$ \\
\hline
\end{tabular}


Table 6. Correlation matrix and probabilities (in parentheses) of Bald Eagle reproductive results in Florida Bay, $1959-1989$ ( $\mathrm{n}=26$, df $=25$ for all tests). Shading indicates significance.

\begin{tabular}{|c|c|c|c|c|c|c|c|}
\hline 8 & $\begin{array}{l}\text { Aotive } \\
\text { Terrs. }\end{array}$ & $\begin{array}{l}\text { Nest. } \\
\text { Atts. }\end{array}$ & $\begin{array}{l}\text { Nest. } \\
\text { Suce. }\end{array}$ & Young & $\begin{array}{l}\text { Youngl } \\
\text { Act. }\end{array}$ & $\begin{array}{l}\text { Young/ } \\
\text { Att. }\end{array}$ & $\begin{array}{l}\text { Young } \\
\text { Succ. }\end{array}$ \\
\hline Year & $(0.0 .17)$ & $\begin{array}{r}-0.28 \\
(0.16)\end{array}$ & $\begin{array}{r}-0.12 \\
(0.55)\end{array}$ & $\begin{array}{l}0.05 \\
(0.81)\end{array}$ & $\begin{array}{l}-0.11 \\
(0.58)\end{array}$ & 0.21 & $\begin{array}{l}0.33 \\
(0.09)\end{array}$ \\
\hline $\begin{array}{l}\text { Act. } \\
\text { Terr. }\end{array}$ & & $\begin{array}{c}-0.01 \\
(0.97)\end{array}$ & $\begin{array}{l}0.14 \\
(0.47)\end{array}$ & $\begin{array}{l}0.36 \\
(0.07)\end{array}$ & $\begin{array}{l}0.09 \\
(0.66)\end{array}$ & 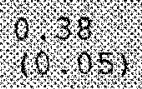 & 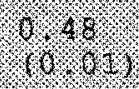 \\
\hline $\begin{array}{l}\text { Nest } \\
\text { Att. }\end{array}$ & & & 10.5 & $(6.50 .01$ & $(0.6 .8$ & $\begin{array}{l}-0.18 \\
10.37)\end{array}$ & $\begin{array}{l}-0.01 \\
(0.98)\end{array}$ \\
\hline $\begin{array}{l}\text { Nest } \\
\text { Suce. }\end{array}$ & & & & 10.00 & $(0.07,0)$ & $(0.5 .80$ & $\begin{array}{l}0,01 \\
(0.94)\end{array}$ \\
\hline Young & & & & & 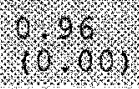 & 6.0 .60 & $(0.6)$ \\
\hline $\begin{array}{l}\text { Youngl } \\
\text { Act. }\end{array}$ & & & & & & 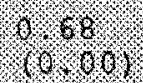 & 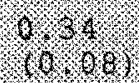 \\
\hline $\begin{array}{l}\text { Young/ } \\
\text { Att. }\end{array}$ & & & & & & & $(0.04)$ \\
\hline
\end{tabular}


Table 7. Correlations and probabilities (in parentheses) of Bald Eagle reproductive activity and adult population, $1959-1989 \mathrm{~h}=26$, df $=25$ for all cells). Shading indicates significance.

\begin{tabular}{|c|c|c|c|}
\hline Act ivity & $\begin{array}{l}\text { Nesting } \\
\text { Adults }\end{array}$ & $\begin{array}{l}\text { Nonnesting } \\
\text { Adults }\end{array}$ & rotal Raults \\
\hline Active Jerrs. & $-0.01(0.97)$ & $0.01 .(0.00)$ & $(0.28,(0.00)$ \\
\hline Nest. Atts. & 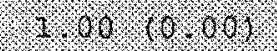 & $0.65(1,00)$ & $(0.47)(0.0 .1)$ \\
\hline Nest. Succ. & $6.66 \%(10)$ & $-0.31 \quad(0,12)$ & $0.34 \quad(0.08)$ \\
\hline Young Fledged & 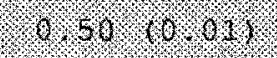 & $-0.19(0.34)$ & $(0.40,(0)(4)$ \\
\hline Young/Act. Terr. & 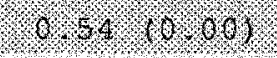 & $-0.34(0,08)$ & $0.28 \quad(0.16)$ \\
\hline Young/Nest. Att. & $-0.18(0.37)$ & $0.26 \quad(0.19)$ & $0.07(0.70)$ \\
\hline Young/Succ. Nest & $-0.01 \quad(0.98)$ & $0.21 \quad(0.29)$ & $0.24 \quad(0,22)$ \\
\hline
\end{tabular}




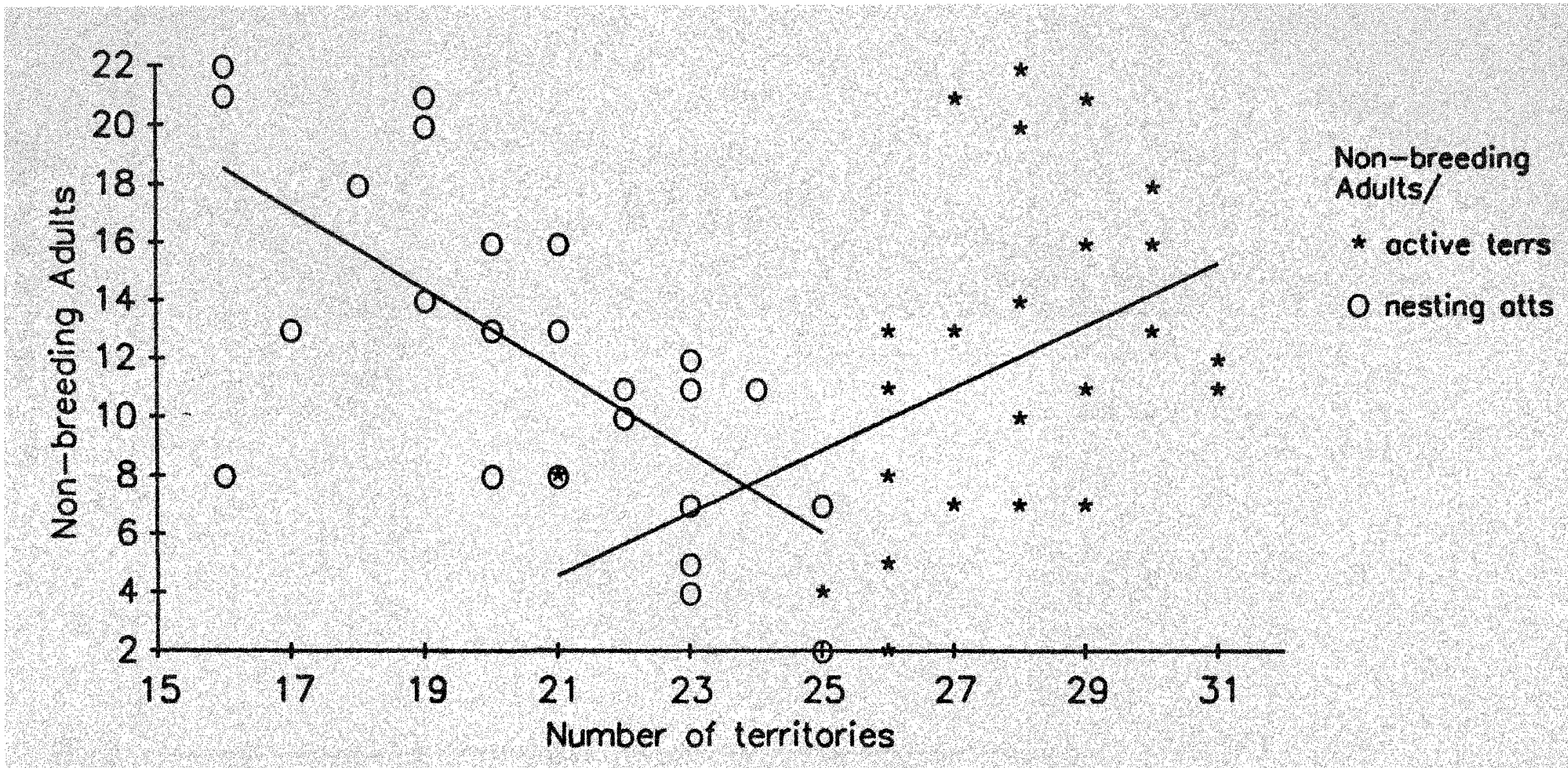

Figure 18. Number of nonbreeding adult Bald Eagles vs number of active territories and nesting attempts, Florida Bay, $1959-1989$. 


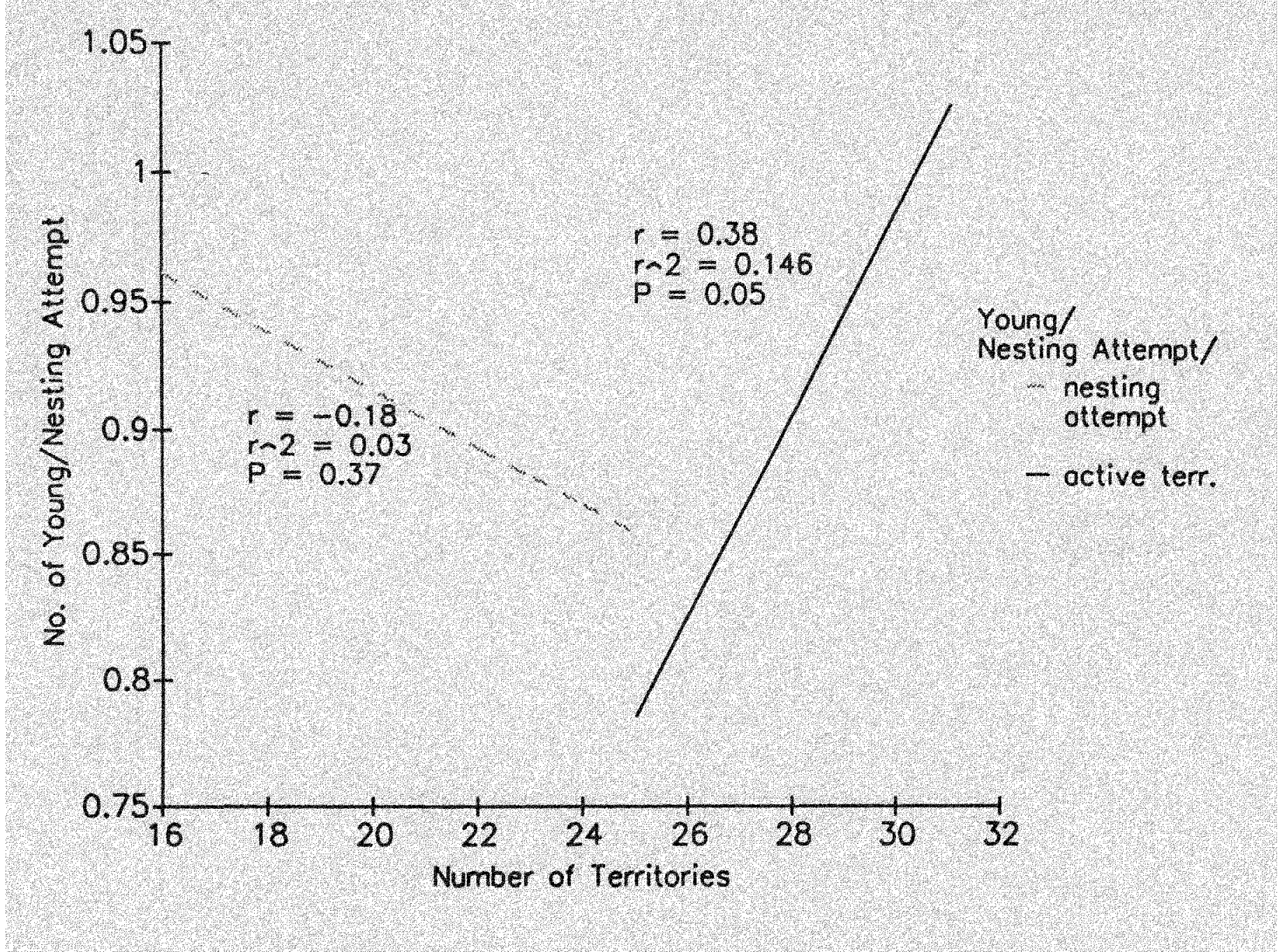

Figure 19. The relationship between the number of Bald Eagles produced per nesting attempt and the number of active territories and nesting attempts, Elorida Bay, $1959-1989$. 


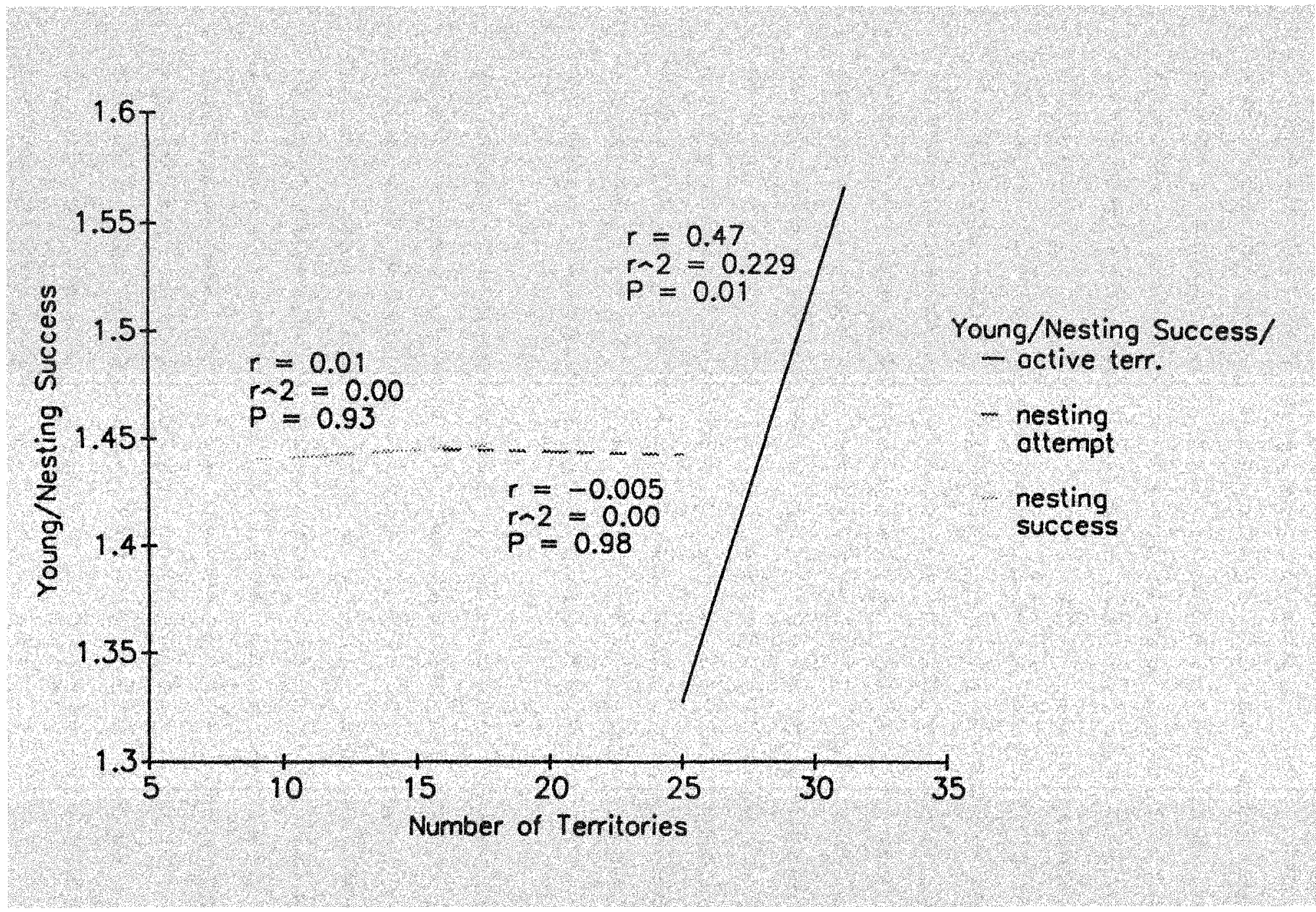

Figure 20. The relationship between the number of Bald Eagles produced per successful nesting attempt to the number of active territories, nesting attempts and nesting successes, Florida bay, $1959-1989$. 
Factors Affecting Nesting Success - There were 182 nesting failures where observations included at least one date of incubation and one date of postnesting activity. I calculated the date of failure as the middle date between the two observations. Most failures ( $n=160,87.9 \%$ ) occurred during the incubation stage, however $9.6 \%$ (17) occurred while downy chicks were present in the nest and $2.7 \%$ (5) occurred with feathered chicks present. The mean date of failure in the incubation stage was 221.1 (6 February) \pm 4.76 , in the downy chick stage it was 247.5 (4 March) \pm 13.73 , and for the feathered chick stage 271.8 (29 March) \pm 11.84 . There were differences between years for dates of failure in the incubation stage (ANovA, $F=1.791$, df $=159, P$ $=0.02$ ) (Eig. 21). I correlated the dates of failure with all of the reproduction parameters, availability of fish (by quarter and annual, see below), and rainfall (annual, monthly through the nesting season and cumulative through the nesting season). There were no significant correlations except cumulative rainfall during the nesting season $(x=0.48$, $d f=16, P=0.05)(E$ ig. 22). I compared the distribution of the observed monthly rainfall from November through April to the distribution of rainfall during the months in which each nest failed. The distributions differed significantly $\left(X^{2}=41.97\right.$, df $\left.=13, P<0.01\right)$, suggesting that high rainfall may adversely effect reproductive success (Eig. 23).

The success of a nesting attempt was independent of changes of nests or nest sites. Attempts at nests that had been used the previous year showed no difference in success rate $v$. those in newly built nests $\left(X^{2}=3.057\right.$, $d f=1$, P>0.05). Nesting attempts made at sites not used the previous year also showed no difference in success rates $v$. those at established sites $\left(X^{2}=\right.$ $2.089, \mathrm{df}=1, \mathrm{P}>0.05)$. However, success was dependent on the performance of the previous year. Territories that had been successful the year before were more likely to be successful than those that had failed $\left(X^{2}=11.84\right.$, df $=1$, $\mathrm{p}<0.005)$. Within territories $70.9 \%$ of nesting attempts were successful following a successful year and only $51.7 \%$ were successful following failures the year before. 


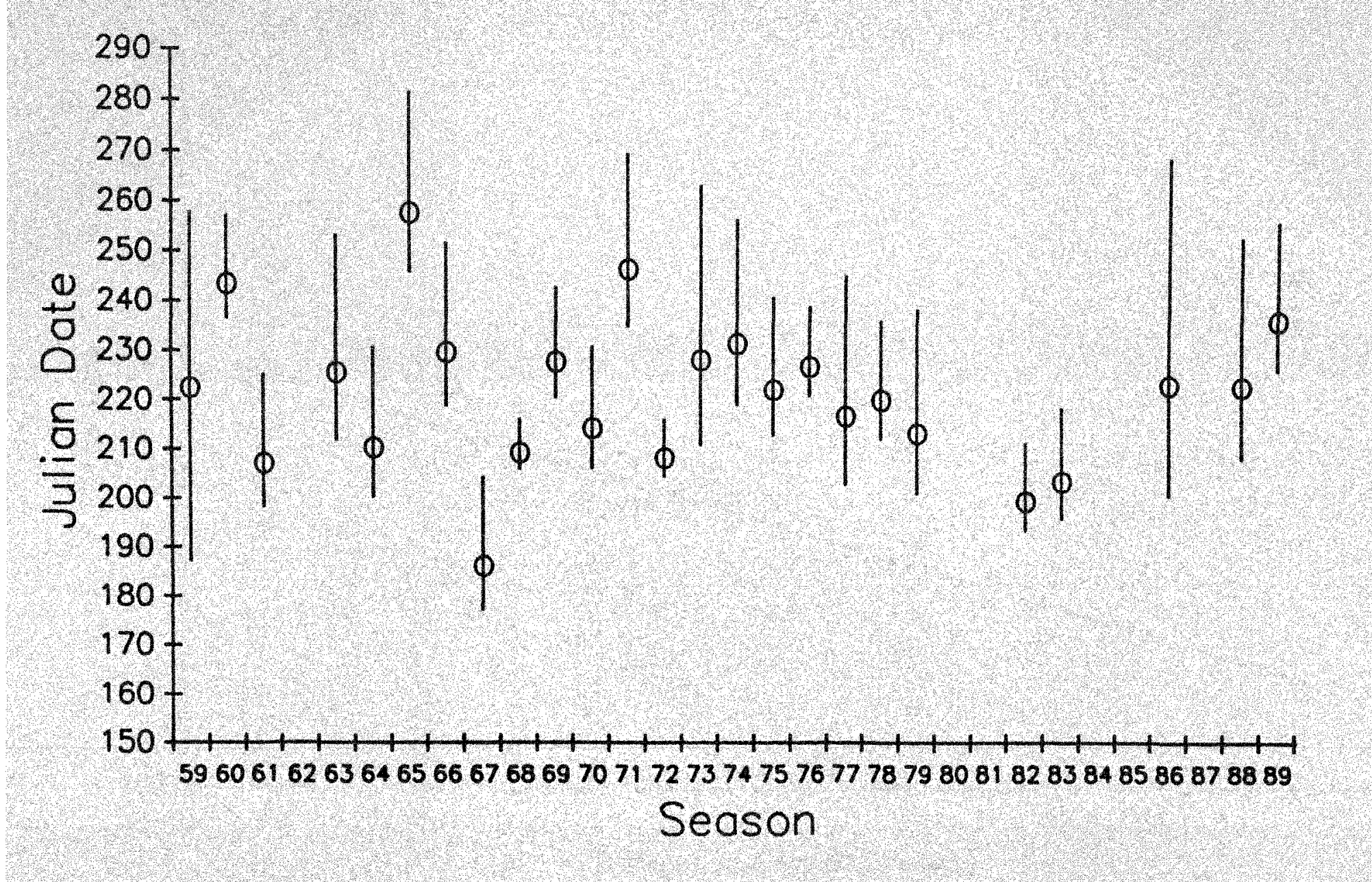

Figure 21. Mean dates and ranges of Bald Eagle nesting failure in Florida Bay when nests were in the incubation stage, $1959-1989$. 


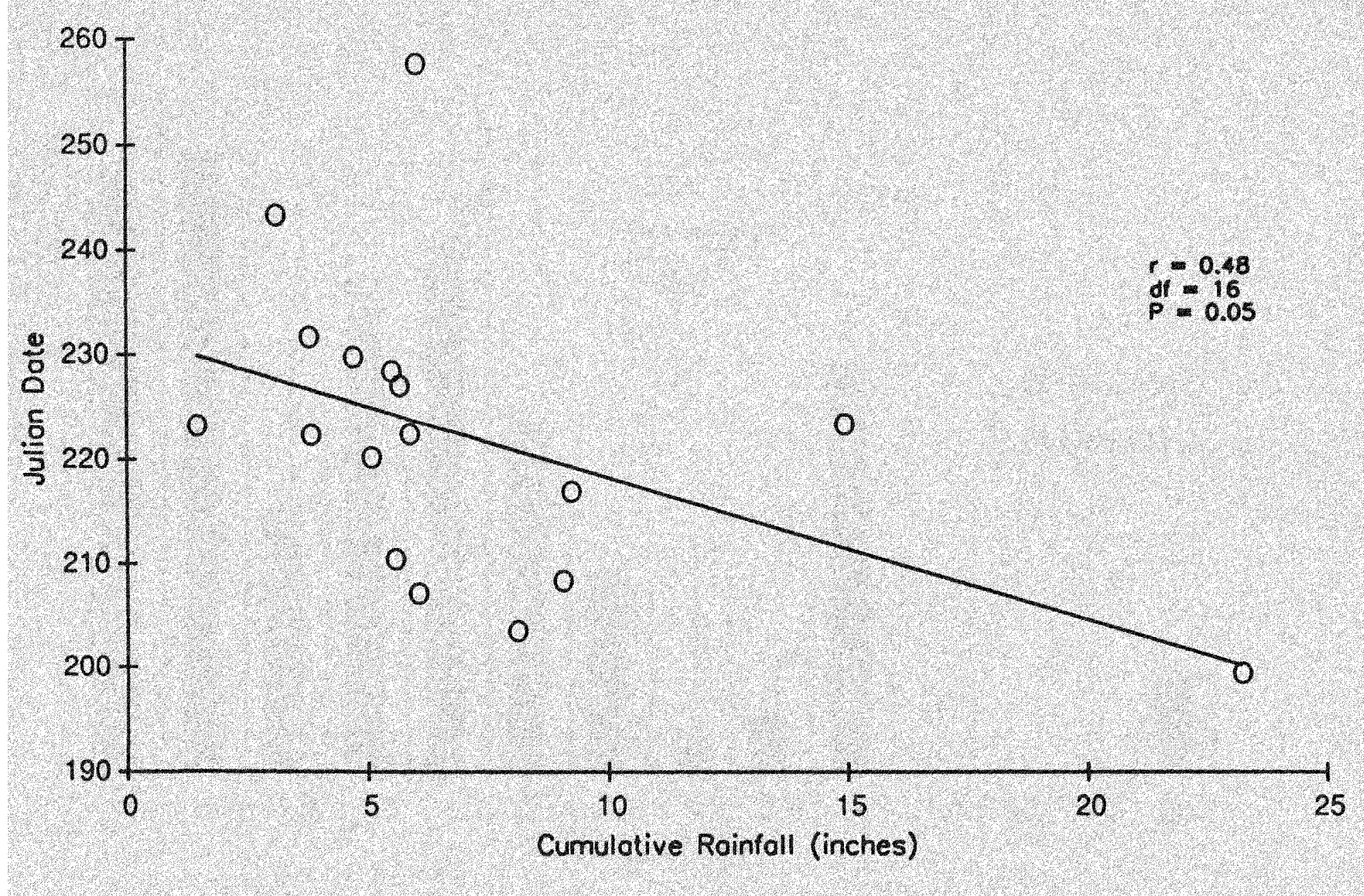

Figure 22. Mean date of Bald Eagle nesting failure in Florida Bay vs cumulative rainfall (in inches) during the nesting season (Dec - Mar), $1959-1989$. 


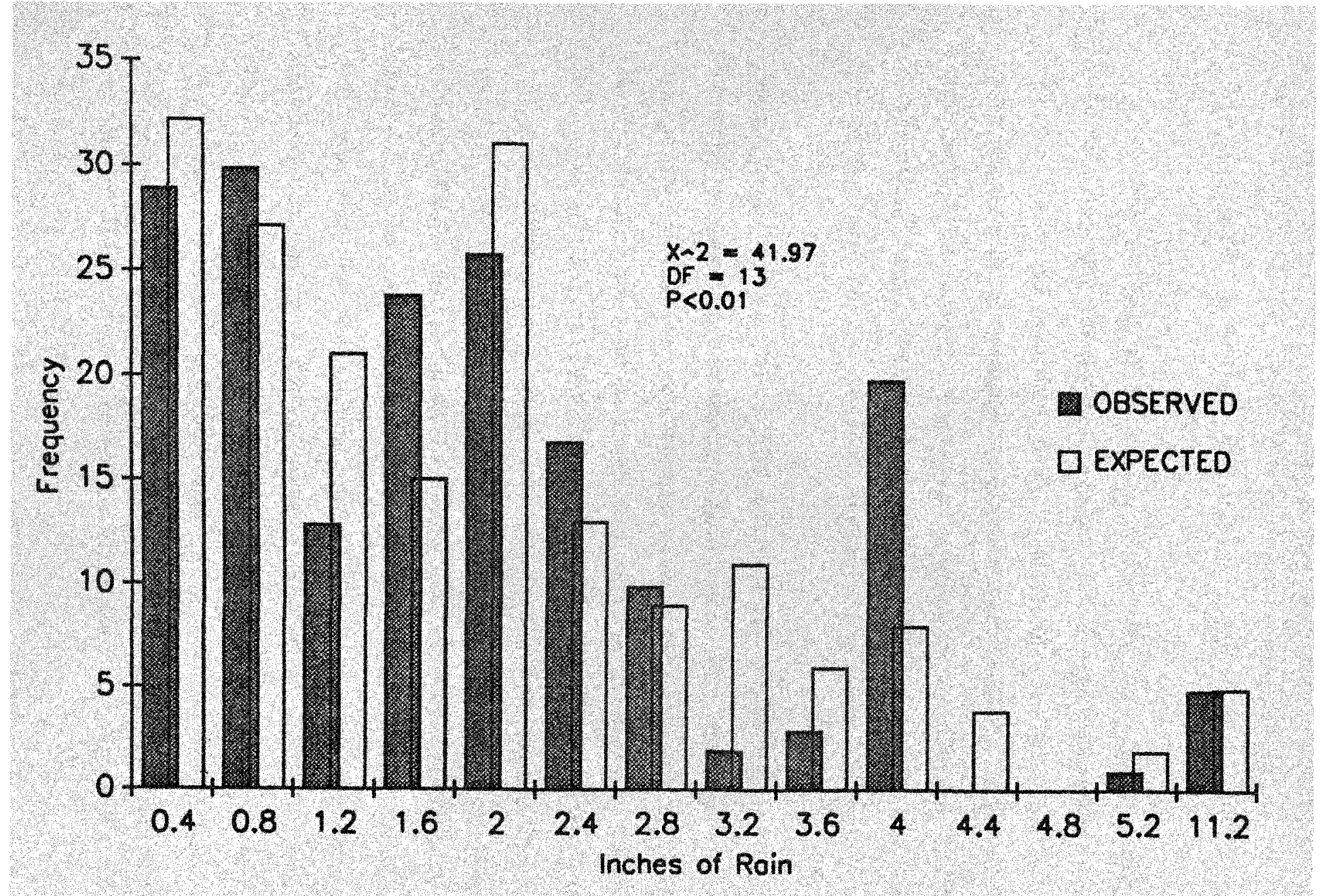

Figure 23. Observed frequencies of monthly rainfall when Bald Eagle nesting failures occurred vs those expected by the distribution of all Nov - April monthly totals, Florida Bay, $1959-1989$. 
There were no significant relationships between reproductive success and density of nesting territories based on regressions for each territory of: nesting success/nesting attempt, young/nesting attempt, and young/nesting success against the mean distance to the nearest active territory for the period of study $(\mathrm{df}=30:$ success/attempt, $r=0.01, \mathrm{P}=0.94$; young/attempt, $\mathrm{I}=0.02, \mathrm{P}=0.89 ;$ young/success, $\mathrm{r}=0.04, \mathrm{P}=0.84$ ).

I used the number of fish caught per man-hour by recreational fisherman in Elorida Bay (M. Schirripa, unpubl, data, South Elorida Research Center, ENP) as an index of piscine prey abundance for Bald Eagles. There were no significant relationships between catch/hour for Jul-Sep, Oct-Dec, Jan-Mar, Apr-Jun, and yearly averages against the numbers of nesting attempts, successful nests, successes/attempt, young produced, young/attempt, and young/success for 18 seasons (using regression analysis).

Nest-sites - There were 206 Bald Eagle nests at 156 sites discovered in. Florida Bay during the study. Some nests were visited and measurements taken of various parameters but others were described only from aerial survey data. As a result, the sample sizes for various parameters were different. Black Mangrove (Laguncularia racemosa) and White Mangrove (Avicenia germinans) were the most common nest trees in Florida Bay accounting for 170 ( 82.5 \%) of the nests. Of these, more than half (101, 59.4\%) were snags (standing dead trees). Red Mangrove (Rhizophora mangle) was the nest tree species in 24 (11.6\%) cases, and most of these (70.1\%) were living. The only other species of tree used for nesting by Bald Eagles was a single Ficus sp. tree with two nests built in it. Three nests (1.5\%) were initially built on the ground. Table 8 summarizes the distribution of all nests as to tree species and condition. Since the growth habits of Avicennia and Languncularia are very similar and the ability to tell them apart during aerial censusing is extremely difficult, I refer to them both as Avicennia and I combined them for analysis vs Rhizophora. 
Table 8. Types of nest trees used by Bald Eagles in Florida Bay, $1959-1989$ seasons. Snags are standing dead trees and "partially live" are trees with a dead center stem and live sprouts emanating from the base.

\begin{tabular}{lllll}
\hline Tree Species & Snags & Live & Partially Live & Total \\
\hline $\begin{array}{l}\text { Avicenia and } \\
\text { Laguncularia }\end{array}$ & 101 & 52 & 17 & 170 \\
Rhizophora & 1 & 17 & 4 & 24 (2 unknown) \\
Other sp. & 2 & 1 & & 3 \\
Ground & & & & 3 \\
\hline \hline
\end{tabular}


The average diameter at breast height (DBH) for all nest trees was $33.4 \pm$ $2.947 \mathrm{~cm}(n=61)$ and average tree height was $4.72 \pm 0.604 \mathrm{~m}(\mathrm{n}=59)$. Height of nest rims averaged $3.96 \pm 0.381 \mathrm{~m}(\mathrm{n}=99)$ and was strongly correlated with nest tree height $(x=0.805, \mathrm{df}=41, \mathrm{P}=0.000)$. Nests averaged $1.29 \pm 0.166$ $m$ in diameter $(n=26)$ and $0.89 \pm 0.164 \mathrm{~m}$ deep $(n=23)$. DBH was not significantly different between Rhizophora nest trees and Avicennia nest trees $(t=0.917, \mathrm{df}=55, \mathrm{P}=0.186)$ nor between dead and alive $(t=0.581$, $\mathrm{df}=52, \mathrm{P}=0.281)$. Rhizophora trees were taller $(t=3.537, \mathrm{df}=52, \mathrm{P}=$ $0.0004)$ and perhaps as a result, living nest trees were taller than dead ones $(t=2.993$, df $=47, P=0.002)($ Tables 9 and 10$)$. At 12 nest-sites I measured the height $(\geq 2 \mathrm{~m})$ of the four nearest trees and compared the $95 \%$ confidence interval with the height of the nest tree las in wood et al. 1989). At only two of the 12 sites was the nest tree significantly taller (emergent). However, I believe that the growth habits of mangroves (i.e., a large central stem with numerous smaller stems either emanating from underground roots [Avicennia] or from prop-roots [Rhizophora]) make traditional measures of nearest neighbor attributes inapplicable. Most Bald Eagle nest-sites appear to be of three general types in Florida Bay: 1) large diameter, hurricane-killed trees, completely isolated in mud-flats; 2) trees or small groups of trees that form isolated clumps with living or dead central stems; and 3) relatively mature trees located in the mangrove fringe that encircles most keys. This is evident in density (stems/ha) estimates (Krebs 1989) of 12 nest sites in Florida Bay. Three sites had densities of less than 25 stems/ha (type 1 above): 3 sites had densities greater than 2000 stems/ha (type 2); and the remaining 6 sites ranged from 150 to 900 stems/ha (type 3). 
Table 9. Comparison of nest age, $\mathrm{DBH}$ and tree height for Avicenia and Rhizophora Bald Eagle nest trees in Elorida Bay, 1959-1989.

\begin{tabular}{llllll}
\hline & Species & mean $\pm 2 \mathrm{~S} . \mathrm{E}$. & $\mathrm{N}$ & T-value & Rrobability \\
\hline $\begin{array}{l}\text { Age of } \\
\text { Nest } \\
\text { (yrs) }\end{array}$ & Avicenia & $3.75 \pm 0.578$ & 124 & & \\
DBH (cm) & Rhizophora & $4.42 \pm 1.460$ & 19 & 0.835 & 0.202 \\
\cline { 2 - 6 } & Avicenia & $32.65 \pm 3.072$ & 50 & & \\
Tree & Rhizophora & $28.71 \pm 6.454$ & 7 & 0.917 & 0.181 \\
\cline { 2 - 6 } $\begin{array}{l}\text { Height } \\
\text { (m) }\end{array}$ & Avicenia & $4.66 \pm 0.592$ & 49 & & \\
\hline \hline
\end{tabular}


Table 10. Comparison of nest age, DBH, and tree height for dead and Iiving Bald Eagle nest trees, Florida Bay, 1959-1989.

\begin{tabular}{lllllll}
\hline & Condition & mean \pm 2 S.E. & N & T-value & Probability \\
\hline Age of & Dead & $4.09 \pm 0.936$ & 72 & & \\
Nest (yrs) & Living & $4.03 \pm 0.804$ & 58 & 0.0987 & 0.461 \\
\cline { 2 - 6 } & Dead & $33.47 \pm 3.872$ & 24 & & \\
DBH (cm) & Living & $31.98 \pm 3.374$ & 30 & 0.5812 & 0.281 \\
\cline { 2 - 6 } & Dead & $4.21 \pm 0.666$ & 24 & & \\
Height (m) & Living & $6.01 \pm 0.986$ & 25 & -2.993 & $0.002 *$ \\
\hline \hline
\end{tabular}




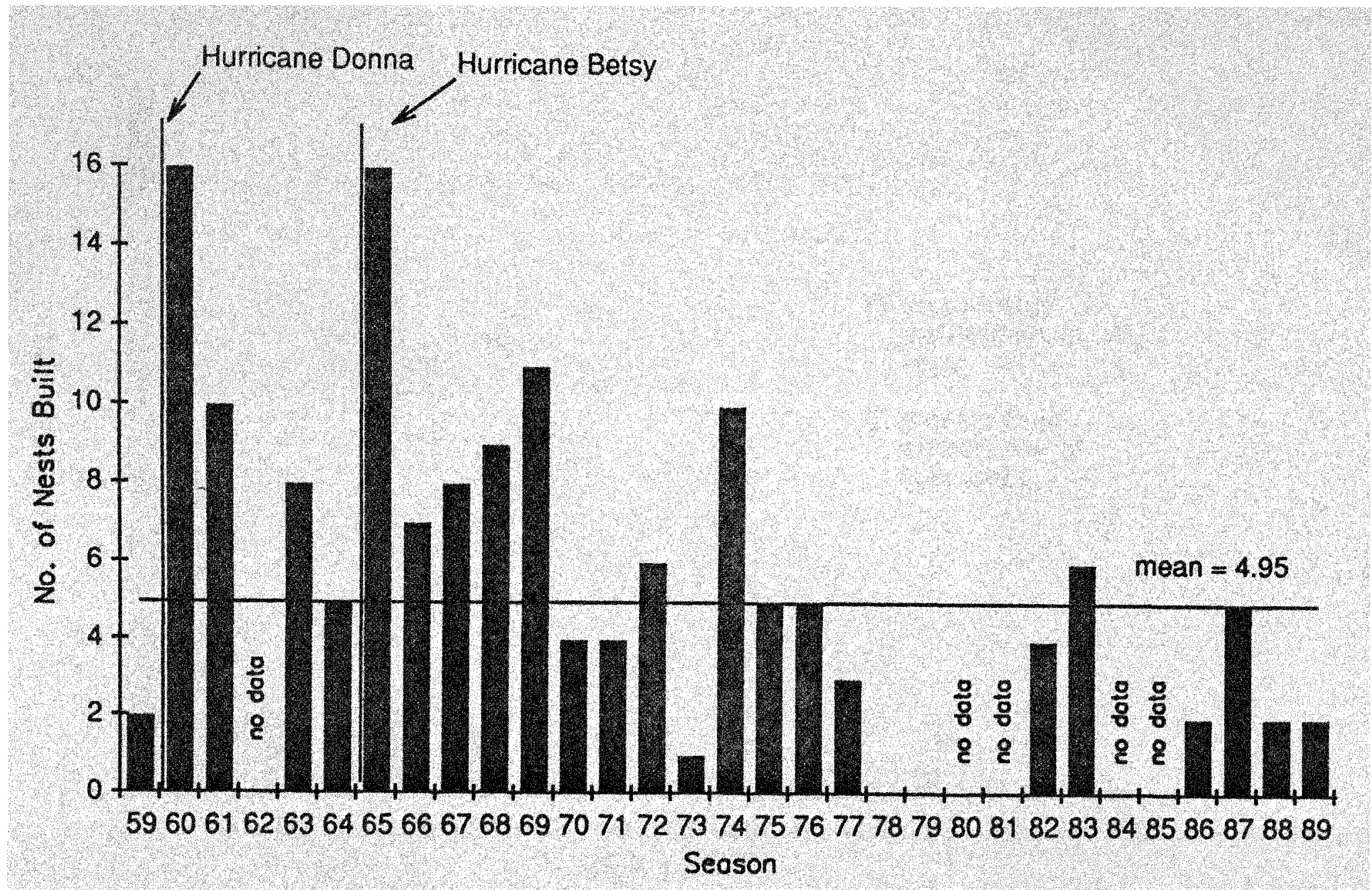

Figure 24. The number of new Bald Eagle nests built each season in Florida Bay, 1959 - 1989. The mean of 4.95 nests does not include seasons 1960 and 1965 . 


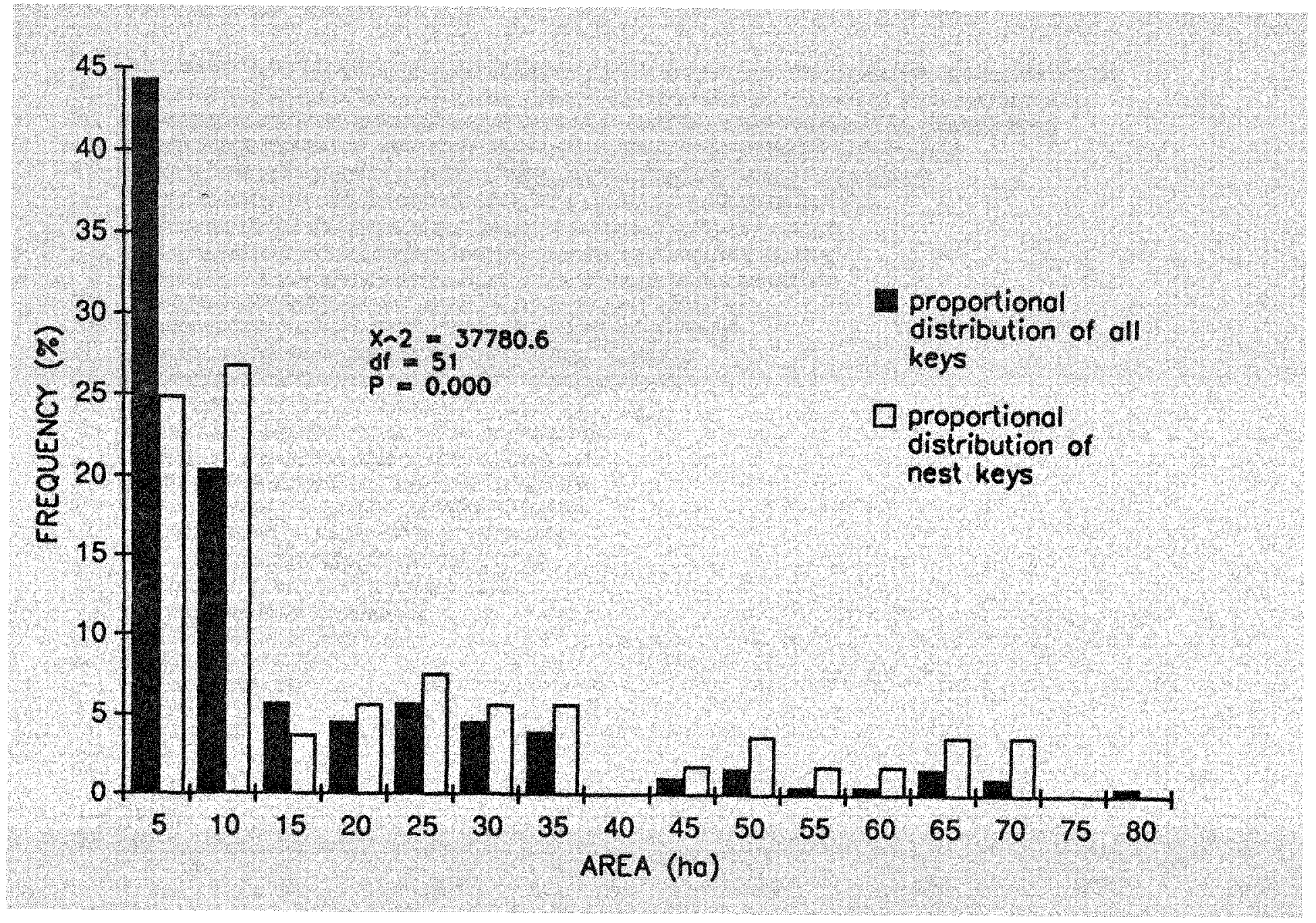

Figure 25. The proportional distribution of the area (ha) of all keys in Florida Bay vs those on which Bald Eagles have nested, 1959 - 1989. Two keys (163.4 ha and 318 ha) are not included, neither had nests. 


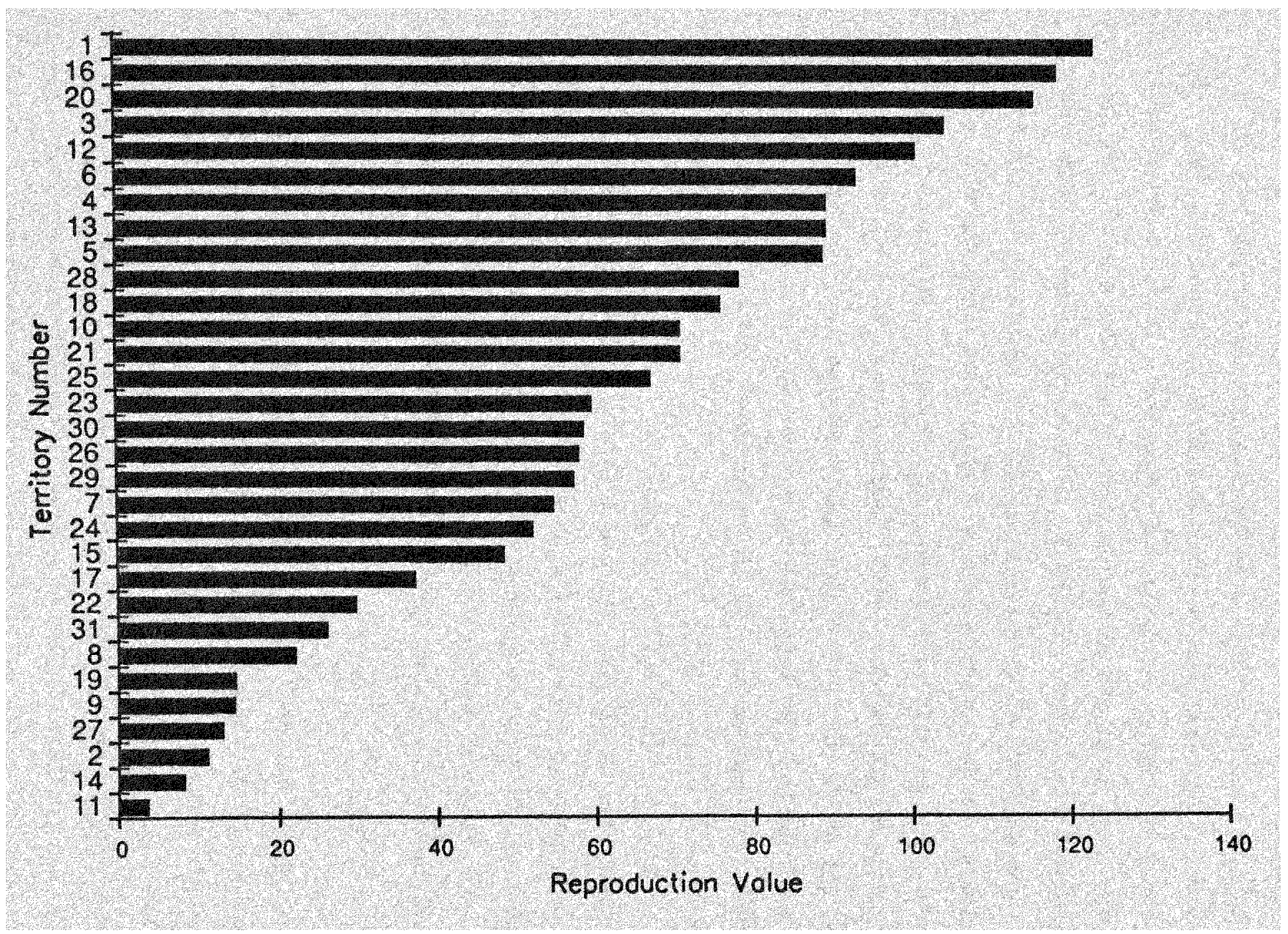

Figure 26. Reproductive values ( 8 seasons active $x$ ave. number of young fledged/active season) for 31 Bald Eagle nesting territories in Florida Bay, 1959 - 1989. 
After being built, nests lasted an average of $3.84 \pm 0.536$ seasons. The species of nest tree had no effect on the longevity of nests $(t=0.835$, df $=141, P=0.203)$, nor did the condition of the tree (live $V$ dead $)(t=$ 0.098 , df $=128, P=0.467)$. New nests were built at an average rate of 4.95 \pm 1.348 per season not counting seasons directly following hurricanes (Fig. 24). In 1960 and 1965 severe hurricanes hit southern Florida just as Bald Eagle nesting activity was beginning. Following each of those storms about half (16) of the nesting pairs in Florida Bay built new nests (Fig. 24). There were 10 occurrences of nests falling during the nesting season. In half of these cases (5) the nesting attempt failed, but in the other half the young survived and were raised to fledging age on the ground. In three cases, young were raised on the ground under the nest even though the nest appeared to be structuraliy sound. These events were probably the result of young nestlings falling out of the nest before they could fly and not having any way to return to it. In four cases, nests fell before the nesting season began and the adults refurbished it on the ground and used it for the following season(s).

Bald Eagles have nested on 52 of the 171 keys in Florida Bay. The keys in the bay range in size from 0.1 ha to 318 ha. Keys with nests ranged from 0.1 ha to 66.6 ha. Figure 25 shows the distribution of the area of all keys in Florida Bay against those used by Bald Eagles for nesting. There was a selection for larger keys by nesting Bald eagles $\left(X^{2}=37780.6\right.$, df $=51$, $\mathrm{P}=$ $0.000)$

Reoroductive quality of Territories - Given that different territories had different levels of activity and different numbers of fledglings produced, I calculated a value of reproductive quality for each of the 31 Bald Eagle nesting territories in Florida Bay. The quality of each territory is the product of the proportion of seasons in which the territory was active and the average number of young fledged from that territory per active season. Values of reproductive quality are shown in Figure 26 (see Figure 7 for locations corresponding to territory numbers). For each territory I 
calculated a linear regression between quality values and distance from East Cape Sable to determine if quality was dependent on location in the bay. The relationship was not significant $\left(r^{2}=0.04\right.$, df $\left.=30, P=0.256\right)$. To determine if territory quality was related to breeding density I tested the value of a territory and the average distance to its four nearest active neighbors but again the relationship was not significant $\left(r^{2}=0.05, d f=30\right.$, $P=0.2081$.

\section{DISCUSSION}

The intensity of observations attained in this study of Bald Eagle breeding in Florida Bay (mean = 7.31/territory/season) was much greater than most Bald Eagle reproduction studies (i.e., 2/season: Hansen 1987 and Troyer and Hansen 1965; 3/season: McEwan and Hirth 1979) and is above the level of 6/season suggested by Fraser et al. (1984). This is also the longest-running database on Bald Eagle reproduction. For these reasons, the results are more accurate than many short-term, low-intensity studies.

Breeding Chronology - Actual reproductive activity at Bald eagle nests in Florida Bay began in late November with the repair or replacement of nests and lasted into late March when fledging-sized young were present. This is an average of 4 months per successful breeding attempt which is in accordance with the 112 days (35 days for incubation and 77 days for nestling stage) reported in palmer (1988) for a nesting cycle. The earliest date of incubation observed was october 15, and if eggs in fact were present, this would precede the earliest date for Florida reported by Bent (1937) as 26 october. The latest observation of incubation was 12 April, a result of a second nesting attempt after the original nest fell earlier in the season. Bent (1937) also reported the presence of eggs into April.

Population and Distribution - There have been over 450 young Bald Eagles fledged from nests in Elorida Bay from 1959 through 1989 . Yet throughout this period the number of breeding adults has remained relatively constant (around 42 individuals). Whittaker (1975) states that population "stability" 
implies a population steady state where, on the average, births equal deaths. In order to apply this definition to the Florida Bay Bald Eagle population it must be assumed that nearly all of the young produced either died before breeding age or dispersed to other areas. There is no evidence to support either hypothesis. No matter what the definition of stability, the adult population of Bald Eagles in Florida Bay appears constant or stable. Newton (1979) reports that in some raptor species stability of breeding populations has been maintained despite prolonged good production of young. For a stable breeding population to exist there must be a regulating mechanism(s) that prevents it from expanding (or contracting). Newton (1979) described four conditions indicative of a stable breeding raptor population. One of these conditions - the reestablishment of a breeding population after removal by man - does not apply to the Florida Bay Bald Eagle population. Newton's other three conditions and their applicability to this population are described below.

Stability of the breeding population in both size and distribution over many years. - The stability of the population of breeding Bald Eagles in Florida Bay is shown by its limited fluctuations over the period of record. The population fluctuated within $15 \%$ of the mean for 20 of the 26 seasons observed. Three seasons were below $15 \%$ and three were above. The distribution of the breeding population has also been extremely stable. Of the 31 breeding territories, 17 have been active every year of the study and most of the others have been active nearly every year (Fig. 15).

The existence of "surplus" adults, capable of breeding but attempting to do so only when a breeding territory is made available. - In all but 7 seasons there have been some nesting territories that went completely unoccupied. Also, each breeding season from 2 to 22 adults have been observed on established territories where no nesting attempt occurred (Fig. 13). of the 175 cases of non-nesting active territories about $70 \%$ involved 2 adults at a territory and $28 \%$ involved a single adult. This suggests that some pairs in Florida Bay may not breed annually, as has been found with Bald Eagles in 
southeastern Alaska (Hansen and Hodges 1985). These apparently non-breeding pairs are not surplus per se since they are probably established in their territories. The single adults at non-breeding active territories may indicate either: 1) a surplus of adults occupying low quality or unfavorable territories and waiting for better territories to become available, or 2) members of pairs that had lost their mates and were waiting for replacements. The latter case would be indicative of an unstable or declining population that does not appear to be the case in Florida Bay. The hypothesis of surplus, non-breeding adults is supported by the relationship between the number of non-nesting adults and the numbers of active territories and nesting attempts (Fig. 18). Non-nesting adults declined with increased nesting attempts, suggesting that excess adults took part in breeding when conditions permitted. However, as the number of active territories increased so did the number of non-nesting adults. Taken together, these two relationships suggest a stable, saturated nesting population with fluctuating numbers of non-nesting adults. Hansen (1987) related fluctuating numbers of non-nesting adult Bald Eagles to fluctuations in food supply. There is no indication that this is the case in Florida Bay (see below).

In areas where nest sites are not restricted, there is a regular spacing of breeding pairs. - The regular pattern of distribution of Bald Eagle nesting territories in Florida Bay is indicated in Figure 8 . Even though the number of active territories ranged from 27 to 31 seasonally their distribution never approached a random or clumped pattern.

Newton (1979) suggested a hierarchical explanation for the limitation of a breeding raptor population. In most cases, availability of prey is the limiting factor, followed by the availability of nest-sites, and finally, the availability of nest-sites that are far enough away from other breeding pairs.

The independence of reproductive parameters from fish availability (see Results) makes it highly unlikely that food is a limiting factor in Bald 
Eagle breeding densities in Florida Bay. Unlike Ospreys (Pandion haliaetus), which are obligate fish predators and occasionally suffer reduced production due to food stress (KushIan and Bass 1983), eagles in Florida Bay are able to shift their prey preferences in response to availability (Robertson, pers. comm.). Prey remains collected from Bald eagle nests in Florida Bay have included over 20 species of birds and over 10 species of fishes (Curnutt, unpubl. data).

Although I did not analyze the availability of suitable nest-sites in Florida Bay, there is nothing to suggest that this may be a limiting factor in the distribution or number of breeding Bald Eagles. Nearly all of the nest-sites described were in the most common tree species in the bay (Avicenia and Rhizophora spp.), and many of these were not emergent, nor of exceptional size. Also, the variety of nest types observed (in trees, under trees after initial nest fell, on ground) suggests a lack of specialization and a consequently high availability of sites. The preference by eagles to nest on larger keys may impose some limits but many larger keys did not harbor nests. It is possible that a "suitable" nest-site would be one where mammalian predators were absent (i.e., Bald Eagles in Alaska avoided islands inhabited by Arctic Foxes Alopex lagopus, Sherrod et al. 1977). Robertson (pers. comm.) suggested that the complete lack of nesting activity on some apparently suitable keys in central Florida Bay and the near absence of nesting attempts on the mainland adjacent to the bay ( 3 of 544 attempts) may be the result of eagle avoidance of areas where raccoons (Procyon lotor) were present. Although there has not been an inventory of the distribution of raccoons in Florida Bay, they have been observed on a number of keys in the central part of the bay and have been seen crossing expanses of exposed mudflats at low tide.

The regularity of the distribution of active Bald Eagle territories in Florida Bay suggests that breeding density may be limited by territorial behavior. Although I have no data on defended home-ranges in Florida Bay, there have been a number of casual observations of nesting adult eagles 
encountering and driving other adults from their nesting key. Bald Eagle terxitory size has been estimated by using distances (or half-distances) between active nests (Howell 1937, Broley 1947, Grier 1969) but this method is probably in error (Mahaffy and Frenzel 1987). Bald Eagles typically defend an area of variable size around their nests (Gerrard and Bortolotti 1988 ) but very few data are available (Mahaffy and Frenzel 1987). Although regularly distributed, nearest neighbor distances between Bald Eagle territories in Florida Bay ranged from $11+\mathrm{km}$ to $1.5 \mathrm{~km}$, with the greatest concentration of territories in the western bay, south of Flamingo, where there are 6 territories in $40 \mathrm{~km}^{2}\left(0.15\right.$ territories $\left./ \mathrm{km}^{2}\right)$. This variability could be due to patchy habitat or differences in prey availability in different parts of Florida Bay. Raptors nesting in less productive areas tend to defend larger territories than those in more productive areas (Newton 1979).

The obvious stability of the breeding population of Bald Eagles in Florida Bay is apparently not shared by the sub-adult population. The decline in the number of sub-adults observed per hour of aerial survey (Fig. 14) may indicate low survival of Bald Eagles at some stage between fledging and breeding age. A recent decline in sub-adults is also supported by data I collected at the communal roost near Mahogany Hammock, ENP. I observed the roost monthly from March 1990 to February 1991 and found at most 14 subadults present. In the late $1960 \mathrm{~s}$ and $1970 \mathrm{~s}$, Robertson and others made observations at the roost and regularly found $20+$ sub-adults (Robertson, pers. comm.). Without individually marked birds the survival and dispersal of eagles fledged from Florida Bay cannot be known.

Reproduction - Bald Eagle reproduction in Florida Bay is stable and is well above the 0.7 young per nesting attempt that sprunt et a1. (1973) felt was necessary for a population to maintain itself. The number of young per nesting attempt and success in Florida Bay is higher than that reported for eagles in all of Everglades National Park, Michigan, Maine, and the western Great Lakes (Sprunt et al. 1973) and is similar to Alaska, Wisconsin, and 
central Florida (McEwan and Hirth 1979, Sprunt et al. 1973) (Fig. 17). The highest value in Figure 17, reported by Troyer and Hensel (1965), may be a result of low sample size $(n=1)$. McEwan (1977) reported 50\% higher Bald Eagle productivity in central Florida than in Everglades National Park. While production in numbers of young produced per attempt and success are slightly higher for central Florida (as reported in McEwan and Hirth (1979) the difference is not that great. The central Florida nests produced significantly more young per attempt $(t=-2.204$, df $=31, \mathrm{P}=0.01)$ but not per success $(t=-1.19$, df $=31, P=0.121)$. Considering that Bald Eagles in Florida Bay are near the extreme southeastern limit of the species' range, it is surprising that they reproduce at comparable levels as those found elsewhere.

The factors that influence the outcome of Bald Eagle nesting attempts in Florida Bay include chronology, rain, the number of active territories, and past success in a territory. Nesting that started early in the season was more successful than later attempts. This has been found to be the case for most raptor species (Newton 1979) and was true for Bald Eagles in Florida (Broley 1947) and southeastern Alaska where Hansen (1987) found increased food supply brought on earlier nesting. Nesting commenced earlier and lasted longer in western Florida Bay than eastern Florida Bay (Fig. 12) but there were no differences in breeding success between the areas. This suggests that the eastern part of Florida Bay may not be as productive as the western part and eagles in the east must take more time to raise the same number of offspring as those in the west. Heavy rain has been found to adversely effect Osprey breeding success (Newton 1979). I found that months with high rainfall had more nesting failures than expected (Fig. 23), and rainfall had no relationship to timing of nesting, suggesting that the adverse effect of rain is on either the adult, the eggs or the young (i,e., hypothermia). The better than expected chance for a pair of Bald Eagle in Florida Bay to succeed at a nesting attempt if the same territory was successful the year before indicates the establishment of experienced pairs. In Saskatchewan, Gerrard and Bortolotti (1988) observed that pairs of eagles occasionally 
failed to nest the year following a failure, and conversely, succeed more often the year following success.

There is no evidence of a relationship between density and reproduction among the Bald Eagles of Florida Bay. Reproductive success was independent of distance to the nearest active territory. This was also found with Bald eagles in central Florida (McEwan 1977) and it suggests that although territories in the bay may be equally productive they must be spaced in a manner that avoids deleterious effects of competition. The relationships between the number of active territories and the number of young produced per nesting attempt and nesting success are puzzling (Fig. 19 and 20). While the number of young produced per nesting attempt is independent of the number of nesting attempts, indicating no density dependence, it is positively correlated to the number of active territories. This is possibly the result of environmental variability where some seasons are more productive for all adults (breeding and non-breeding), which leads to higher occupancy of territories as well as higher production of young.

A very large proportion (87\%) of the nesting failures of Bald Eagles in Florida Bay occurred during the incubation stage. Newton (1979) synthesized a number of raptor breeding studies and noted that more birds fail near the start of the breeding season than near the end. He believed that shortages in food supply was probably the ultimate cause for most nest failures, acting on the adults either while nesting is occurring lleading to desertion of eggs or young) or before the breeding season begins (inhibiting the females production of eggs). More data on prey availability and energy budgets of Bald Eagles in Florida Bay are needed before this hypothesis can be tested. other causes for desertion of nests include human interference, pesticides, and weather (Newton 1979). Human interference does not appear to be a factor in nest failure in Florida Bay. Most nests are inaccessible and unknown to the public and nests that were closest to human development (i.e., territory nos. 5, near Key Largo, and 25, near Flamingo) did not have exceptionally low reproductive value (Fig. 26). In Florida Bay, the only significant 
relationship I could find with mean date of failure was cumulative rainfall during the breeding season. High rainfall correlated with early nest failure. Whether the rainfall affects the birds on the nest or some aspect of behavior (i.e., food deprivation due to effects of rain on ability to forage or behavior of prey species) is not clear.

Relationships between reproduction and nest site - Bald Eagles in Florida Bay did not respond to changes in nests or nest sites by lowering productivity as has been found in other populations (i.e., Gerrard and whitfield 1979, Swenson et al. 1986). This may be an evolutionary adaptation to the relatively short lifespan of eagle nests in Florida Bay. Nests lasted an average of 3.84 seasons compared to 5 seasons in Saskatchewan (Gerrard et al. 1983) and 20 seasons in Alaska (Hodges 1982). The measure of reproductive quality I assigned to each territory showed a large range (4 to 122 ). Although this value would seem to a measure of the productivity of each area in terms of providing the necessary prey, etc. to breeding Bald Eagles, Newton (1979) warns against such assumptions. He stated that reproductive success of a territory may be due to the combined effect of the best birds getting the best territories, while lower quality breeders (i.e., younger or less adept) are left with lower quality sites. The quality of territories was independent of location in the bay and of density of territories. Other hypotheses such as differences in prey availability or territorial behavior should be tested.

Nest Sites - Nest sites of Florida Bay Bald Eagles are different from those of any other populations studied in both preferred tree species and proportion of dead trees used (Table 11). Eagles in Florida Bay basically have no choice but to use mangroves for nest trees since there are few trees of any other species present. The affinity that Bald Eagles have for pine trees however does show itself in their use of the pines near Mahagony Hammock, $20 \mathrm{~km}$ north of Florida Bay, as a night roost for birds that forage in the bay (Curnutt, unpubl. data). The use of dead trees to nest in is very rare in other parts of the Bald Eagle's range. Many authors (i.e., Gerrard 
and Bortolotti 1988, wood et al. 1989) have suggested that eagles select for Iiving trees, perhaps because they offer more permanent support than dead ones (Mathisen 1983). However, mangroves, especially Avicenia, seem to remain structurally sound for many decades after they die as is evident in the number of large trees still standing that were killed by the "Labor Day" hurricane in 1935 (Robertson, pers. comm.). Thus, in Florida Bay, dead trees may offer one of the most secure foundations for eagle nests.

As in the Aleutian Islands (Sherrod et al. 1977), the lack of mammalian predators on most of the keys in Florida Bay allowed for ground nesting by Bald Eagles. In most cases, ground nests resulted from tree nests that had fallen and were refurbished as they lay but three nests were initiated on the ground. Ground nests, as reported in shea et al. 1979, were relatively rare (7) of 206 nests) suggesting that there were ample suitable nest trees available. Bald Eagles selected the larger keys in Florida Bay for nesting. This may be a result of the spatial distribution of the larger keys themselves or a preference for larger, drier keys instead of the smaller ones, many of which have very little soil and are inundated by high tides. The 10 cases of nests falling during the breeding season and three cases of young being successfully raised on the ground under nests may suggest evolutionary selection against nesting on small inundated keys. At such nests, nestling eagles would surely die in case of a collapsed nest. 
Table 11. Characteristics of Bald Eagle nest sites from various studies.

\begin{tabular}{llllll}
\hline Location & N & Dominant tree sp. & Dead & Emergent & Citation \\
\hline Oregon & 192 & $\begin{array}{l}\text { Pseudotsuga } \\
\text { menziesii }\end{array}$ & 0 & $65 \%$ & Anthony and Isaacs 1989 \\
Louisiana & 29 & Taxodium distichum & 0 & $93 \%$ & Harris et a1. 1987 \\
Alaska & 324 & Populus trichocarpa & Troyer and Hensel 1965 \\
Maryland & 70 & Pinus taeda & rare & Andrew and Mosher 1982 \\
Minnesota & 292 & Pinus strobus & $4 \%$ & most & McEwan and Hirth 1979 \\
Florida & 61 & Pinus sp. & $10 \%$ & $19 \%$ & Wood et al. 1989 \\
Florida & 116 & Pinus sp. & $53 \%$ & few & \\
Florida Bay & 206 & Avicenia & &
\end{tabular}


CONCLUSION

This study reveals the breeding population of Bald Eagles in Florida Bay to be stable and saturated. There are, however, questions that should be addressed. The population of eagles in Florida Bay is only part of a greater population of Bald Eagles that nest from the Lower Keys north along the Gulf Coast to at least Naples. The analysis of the Florida Bay sub-population is only the first step in an assessment of all Bald Eagles in southern Florida. With its high level of stability and consistent production of young Florida Bay may act as a core population, which could remain saturated even as surrounding populations decline. A more comprehensive understanding of Bald Eagle population ecology in southern florida should begin with a marking program of both adults and nestlings. This would provide data on survival, sex-ratios and foraging and home-range territories as well as information on dispersal of young. Another aspect of Bald Eagle biology that should be addressed is the apparent reproductive isolation of southern birds from northern ones. With breeding seasons at different times of the year and apparently little movement of northern birds into southern breeding ranges (Eostupalsky [1976] reported only four known cases of marked northern eagles in the south, all less than 1-year old), it is possible that there are two genetically distinct sub-populations of Bald Eagles in eastern North America. This should be addressed by marking individuals and by genetic analysis. 
Amadon, D. 1983. The Bald Eagle and its relatives. pages $1-4$ in Bird, D. M. (Chief Ed.). Biology and management of Bald Eagles and ospreys. Harpell Press, Ste. Anne de Bellevue, Quebec. 325 pages.

Andrew, J. M. and J. A. Mosher. 1982. Bald Eagle nest site selection and nesting habitat in Maryland. J. Wildl. Manage. 46:383-390.

Anthony, R. G. and F. B. Isaacs. 1989. Characteristics of Bald Eagle nests in Oregon. J. Wildl. Manage. 53:148-159.

Barnes, I. R. 1951. Persecution or freedom? Audubon Magazine. $1951(5): 282-289$.

Bent, A. C. 1937. Iife histories of North American birds of prey. Part 1, U.S. National Museum Bull. 167, Washington, D.C.

Bird, D. M. (Chief ed.). 1983. Biology and management of Bald Eagles and Ospreys. Harpell press, Ste. Anne de Bellevue, Quebec. 325 p.

Broley, C. L. 1947. Migration and nesting of Elorida Bald Eagles. Wilson Bulletin $59(1): 30-20$.

Brown, W. H. 1975. Winter population trends in the Bald Eagle. American Birds $29: 12-14$.

Craighead, E.C., Sr. 1971. The trees of South Florida, Vol. 1. University of Miami Press, Coral Gables. 212 pages.

Eraser, J. D., I. D. Erenzel, J. E. Mathisen, E. Martin, and M. E. Shough. 1983. Scheduling Bald Eagle reproduction surveys. Wildlife society Bu11 $11(1): 13-16$. 
Eraser, J. D., E. Martin, L. D. Frenzel, and J. E. Mathisen. 1984. Accounting for measurement errors in Bald Eagle reproduction surveys. J. Wildife Management $48(2): 595-598$.

Fuller, M. R. and J. A. Mosher. 1987. Raptor survey techniques. Eages 37-65 in B. A. Giron Pendelton, B. A. Milsap, K. W. Cline, and D. M. Bird, eds. Raptor management techniques manual. National wildlife Federation, Washington, D. C.

Gerrard, J. M. and G. R. Bortolotti. 1988. The Bald Eagle. Smithsonian Institution Press, Washington. 177 pages.

Gerrard, J. M., P. N. Gerrard, G. R. Bortolotti and D. W. A. Whitfield. 1983. A 14-year study of Bald Eagle reproduction on Bresnard Lake, Saskatchewan. Pages 47-57 in Bird, D. M., chief ed. Biology and management of Bald Eagles and Ospreys. Harpell Press, Ste. Anne de Bellevue, Quebec. 325 p.

Gerrard, J. M. and D. W. A. Whitfield. 1979. An analysis of the "crash" in eagle productivity in saskatchewan in 1975. Pages 42-48 in $\mathrm{T}$. $\mathrm{N}$. Ingraham, ed. Proc. Bald Eagle Conf. on wintering eagles. Eagle Valley Environ., Apple River, Ill. Tech. Rept. BED-79.

Grier, J. W. 1969. Bald Eagle behavior and productivity responses to climbing to nests. J. Wildl. Manage. 33:961-966.

Grier, J.W. 1982a. Ban on DDT and subsequent recovery of reproduction in Bald Eagles. Science 218:1232-1235.

Grier, J.W. 1982b. Bald eagle. pages 48-49 in D. E. Davis, ed. CRC handbook of census methods for terrestrial vertebrates. CRC Press, Inc., Boca Raton, $E l$. 
Grier, J. W., J. M. Gerrard, G. D. Hamilton, and P. A. Gray. 1981. Aerial visibility bias and survey techniques for nesting Bald Eagles in Northwest ontaxio. J. Wildlife Management $45(1): 83-92$.

Hansen, A. J. 1987. Regulation of Bald Eagle reproductive rates in southeast Alaska. Ecology 68(5):1387-1392.

Hansen, A. J. and J. I. Hodges. 1985. High rates of nonbreeding adult Bald Eagles in southeastern Alaska. J. Wildilfe Management 49(2):454-458.

Harris, J. O., P. J. Zwank and J. A. Dugoni. 1987. Habitat selection and behavior of nesting Bald Eagles in Louisiana. J. Raptor Res. 21:2731.

Hodges, J. I., Jr. 1982. Bald Eagle nesting studies in seymore canal, southeast Alaska. Condor 84:125-127.

Howell, J. C. 1937. The nesting Bald Eagles of southeastern Florida. Auk $54: 296-299$.

Krebs, C. J. 1989. Ecological Methodology. New York: Harper and Row, Publishers. $654 \mathrm{pp}$.

Kushlan, J. A. and O. L. Bass, Jr. 1983. Decrease in the southern Florida osprey population, a possible result of food stress. Pages 187-200 in Bird, D. M., chief ed. Biology and management of Bald Eagles and ospreys. Harpell press, Ste. Anne de Bellevue, quebec. 325 p.

Mahaffy, M. S. and L. D. Frenzel. 1987. Elicited territorial responses of Northern Bald Eagles near active nests. J. Wildl. Manage. 51:551-554.

Mathisen, J. E. 1983. Nest site selection by Bald Eagles on the Chippewa National Eorest. Pages 95-100 in Bird, D. M., chief ed. Biology and 
management of Bald Eagles and ospreys. Harpell Press, Ste. Anne de Bellevue, Quebec. $325 \mathrm{p}$.

McCollough, M. A. 1989. Molting sequence and aging of Bald Eagles. Wilson Bulletin 101 (1): 1-10.

McEwan, L. C. 1977. Nest site selection and productivity of the southern Bald Eagle. M. Sc. Thesis, University of Florida, Gainesville. 63 p.

McEwan, L. C. and D. H. Hirth. 1979. Southern Bald Eagle productivity and nest site selection. J. Wildilfe Management 43(3):585-594.

McGehee, S. and W. C. Crawford, Jr. 1985. Captive management and dietary requirements of eagles and ospreys. Wildife Rehabilitation 3:19-23.

Newton, I. 1979. Population ecology of raptors. Vermillion, SD: Buteo Books. 399 p.

Palmer, R. S. (ed.). 1988. Handbook of North American Birds, Vol. 4 (part 1). Yale University Press, New Haven. 433 pages.

Postupalsky, S. 1974. Raptor reproductive success: some problems with methods, criteria, and terminology. Raptor Research Report 2:21-31.

Postupalsky, S. 1976. Banded northern Bald Eagles in Florida and other southern states. Auk 93:835-836.

Shea, D. S., R. E. Shea, and W. B. Robertson, Jr. 1979. Unusual observations of nesting Bald Eagles in South Florida. Florida Field Naturalist. $7: 3-5$.

Sherrod, S. K., C. M. White, and E. S. L. Williamson. 1977. Biology of the Bald Eagle on Amchitka Island, Alaska. Iiving Bird 15:143-182. 
Simons, T., S. K. Sherrod, M. W. Collopy, and M. A. Jenkins. 1988. Restoring the Bald Eagle. American Scientist 76:253-260.

Smith, G. 1969. The declining American Bald Eagle; can it be saved? Florida Wildife. $1969(7): 12-17$.

Sokal, R. R. and F. J. Rohlf. 1981. Biometry. W. H. Ereeman and Co., San Francisco. 776 pages.

Sprunt,A., IV, W. B. Robertson, Jr., S. Postupalsky, R. J. Hensel. C. E. Knoder, and E. J. Iigas. 1973. Comparative productivity of six Bald Eagle populations. North American Wildlife Conference 38:96-106.

Swenson, J. E., K. L. Alt and R. L. Eng. 1986. Ecology of Bald Eagles in the Greater Yellowstone Ecosystem. Wildl. Monogr. 95:1-46.

Troyer, W. A. and R. J. Hensel. 1965. Nesting and productivity of Bald Eagles on the Kodiak National Wildlife Refuge, Alaska. Auk 82:636638.

U.S. Fish and Wildife Service (USFWS). 1990. Proposed review of the status of the Bald Eagle. Endangered Species Tech. Bull. 15(2):3.

Whittaker, R. H. 1975. Communities and ecosystems. New York: MacMillan Publishing Co. $385 \mathrm{p}$.

Wood, P. B., T. C. Edwards, Jr., and M. W. Collopy. 1989, Characteristios of Bald Eagle nesting habitat in Elorida. J. Wildife Management $53(2): 441-449$. 